\title{
Investigating the effect of zirconium oxide microstructure on corrosion performance: a comparison between neutron, proton and non-irradiated oxides
}

DOI:

10.1520/STP159720160069

\section{Document Version}

Accepted author manuscript

Link to publication record in Manchester Research Explorer

Citation for published version (APA):

Garner, A., Baxter, F., Frankel, P., Topping, M., Harte, A., Slater, T., Tejland, P., Romero, J., Darby, E. C., ColeBaker, A., Gass, M., \& Preuss, M.' (2018). Investigating the effect of zirconium oxide microstructure on corrosion performance: a comparison between neutron, proton and non-irradiated oxides. In 18th International Symposium on Zirconium in the Nuclear Industry ASTM International. https://doi.org/10.1520/STP159720160069

\section{Published in:}

18th International Symposium on Zirconium in the Nuclear Industry

\section{Citing this paper}

Please note that where the full-text provided on Manchester Research Explorer is the Author Accepted Manuscript or Proof version this may differ from the final Published version. If citing, it is advised that you check and use the publisher's definitive version.

\section{General rights}

Copyright and moral rights for the publications made accessible in the Research Explorer are retained by the authors and/or other copyright owners and it is a condition of accessing publications that users recognise and abide by the legal requirements associated with these rights.

\section{Takedown policy}

If you believe that this document breaches copyright please refer to the University of Manchester's Takedown Procedures [http://man.ac.uk/04Y6Bo] or contact uml.scholarlycommunications@manchester.ac.uk providing relevant details, so we can investigate your claim.

\section{OPEN ACCESS}


Investigating the effect of zirconium oxide microstructure on corrosion performance: a comparison between neutron, proton and non-irradiated oxides

Alistair Garner ${ }^{1}$, Felicity Baxter ${ }^{1}$, Philipp Frankel ${ }^{1}$, Matthew Topping ${ }^{1}$, Allan Harte ${ }^{1}$, Thomas Slater $^{1}$, Pia Tejland ${ }^{2}$, Javier Romero ${ }^{3}$, Edward C. Darby ${ }^{4}$, Aidan Cole-Baker ${ }^{4}$, Mhairi Gass $^{5}$, Michael Preuss ${ }^{1}$

\section{ABSTRACT}

Automated crystal orientation mapping in the transmission electron microscope has been used to simultaneously map the phase, orientation and grain morphology of oxides formed on Zircaloy-2 after 3 and 6 cycles in a BWR reactor in unprecedented detail. For comparison, a region of a pre-oxidised autoclave-formed oxide was also proton irradiated at the Dalton Cumbrian Facility. The proton irradiation was observed to cause additional stabilisation of the tetragonal phase, attributed to the stabilising effect of irradiation-induced defects in the oxide. In the reactor-formed oxides, no extra stabilisation of the tetragonal grains was observed under neutron irradiation, as indicated by the similar tetragonal phase fraction and transformation twin boundary distributions between the non-irradiated and reactor-formed oxides. It is suggested that the damage rate is too low in the newly formed oxide to cause significant stabilisation of the tetragonal phase. This technique also reveals the oxide formed under reactor conditions has a more heterogeneous microstructure and the growth of well-oriented columnar monoclinic grains is significantly reduced when compared to a non-irradiated oxide. High angle annular dark field scanning transmission electron microscopy (HAADF STEM) also revealed the development of extensive networks of intergranular porosity and eventually grain decohesion in the

\footnotetext{
${ }^{1}$ Materials Performance Centre, School of Materials, The University of Manchester, Manchester M13 9PL, UK

${ }^{2}$ Studsvik Nuclear AB, 61182 Nykoping, Sweden

${ }^{3}$ Westinghouse Electric Company, Hopkins, SC 29061, USA

${ }^{4}$ Rolls Royce, Derby DE21 $7 X X, U K$

${ }^{5}$ Amec Foster Wheeler, Walton House, Faraday Street, Birchwood Park, Risley, Warrington WA3 6GA, UK
} 
reactor formed oxides. The current results suggest that the tetragonal-monoclinic transformation is not responsible for the accelerated corrosion exhibited under reactor conditions. It is proposed that the usual out-of-reactor oxide growth and nucleation processes are significantly modified under reactor conditions, resulting in a more heterogeneous and randomly oriented oxide microstructure with reduced columnar grain growth. It is suggested that this disordered oxide microstructure allows for the formation of extensive intergranular porosity which could lead to accelerated inreactor corrosion.

\section{KEYWORDS}

Oxide microstructure, Zircaloy-2, BWR, Proton-irradiation, tetragonal phase, texture, porosity, TEM, HAADF-STEM

\section{INTRODUCTION}

The corrosion kinetics of zirconium alloys in aqueous environments, in the absence of irradiation, are well known. After an initial period of rapid growth, commercial alloys exhibit cyclic corrosion behaviour, with the repeated build-up and breakdown of the protective oxide [1], [2]. This behaviour has been correlated with the periodicity in the oxide microstructure, with slower oxide growth leading to textured columnar grain formation [3] and transitions in the corrosion kinetics leading to layers of lateral cracks in the oxide and the onset of equiaxed grain morphology [4], [5]. The development of oxide texture is proposed to be driven by the compressive stress in the oxide, with favoured orientations having $(10 \overline{3})$ to $(10 \overline{5})$ planes parallel to the metaloxide interface due to their small in-plane surface area leading to a minimization of the stress in the growing oxide [3], [6]-[9]. The transitions in corrosion kinetics are often attributed to the interconnectivity of pores and cracks in the oxide, allowing the 
cathodic reaction to occur closer to the metal oxide interface [4], [10], [11]. The destabilisation of the tetragonal phase during oxide growth has been cited in the literature as a possible cause of the breakdown of the protective oxide and subsequent transition in corrosion kinetics [7], [12]-[15]. The extensive transformation from tetragonal to monoclinic oxide during growth leads to disruption of the protective oxide and the development of extensive networks of transformation twin boundaries [7], [10], [16], [17]. However, as the corrosion behaviour under irradiation differs from that observed during autoclave exposure [18], many of the mechanisms derived from observations on non-irradiated oxides may no longer be as relevant in the complex reactor environment. As the industry is pushing towards extended burn up, where the corrosion behaviour of the cladding deviates further from out-of-pile tests [19], [20], it is vitally important that the underlying mechanisms of corrosion under irradiation are understood.

After exposure to in-reactor conditions (at an oxide thickness of $\sim 2 \mu \mathrm{m}$ for Zircaloy-2 in pressurised water reactor conditions [21]), a significant enhancement of the out-ofpile corrosion rate is observed [18], [21], [22]. Irradiation-induced dissolution of second phase particles (SPPs) has been shown to cause solute enrichment of the surrounding matrix, leading to enhanced corrosion rates [23], [24]. In addition to the microstructural effects in the substrate, the redistribution of $\mathrm{Fe}$ in the oxide due to irradiation-induced SPP dissolution has been linked to the stabilisation of the tetragonal oxide phase [24]-[26]. Therefore it is likely that the usual out-of-pile oxide growth processes and thus microstructure will be modified under irradiation. TEM examinations of oxides formed under irradiation frequently report contradicting results, probably due to the fact that only a small portion of a thick oxide is usually observed and the oxidation history is unknown. Some authors report the majority of the oxide is composed of monoclinic columnar grains, similar to that formed during 
out-of-pile tests [19], [27], [28]. However, other authors report the formation of randomly oriented nanocrystalline tetragonal oxide grains under neutron irradiation [24], [29], which leads to a highly porous oxide structure. Abolhassani et al. observed columnar grains at the metal-oxide interface, with small quantities of tetragonal oxide at the monoclinic boundaries [30]. These authors also observed equiaxed grains at the metal-oxide interface of a different lamella prepared from the same material, highlighting the heterogeneous oxide microstructure that forms in-reactor. Although oxidation of pre-irradiated alloys has shown a difference in corrosion behaviour [2], [23],[24], a similar oxide microstructure is observed between oxides formed on preirradiated and non-irradiated substrates.

Nano-scale porosity is commonly observed in non-irradiated zirconium oxide films using Fresnel contrast in the TEM [10], [13], [31]-[33]. These pores are often seen to be aligned along the oxide grain boundaries, $1-5 \mathrm{~nm}$ in size and disconnected close to the metal/oxide interface at the pre-transition stage [10], [29], [34]-[38]. In posttransition oxides, the pores tend to become larger and interconnected providing a fast track for diffusing species. However, it is frequently reported that even in posttransition oxides, porosity is rare in the region close to the metal/oxide interface. In this region small disconnected pores are sometimes observed, similar to those observed in pre-transition oxides [35], [39]. Such a protective layer (also referred to as the barrier layer) has also been reported when interrogating oxides by means of electrochemical impedance spectroscopy (EIS), which has estimated the thickness of the post-transition barrier layer to be between $\sim 0.5 \mu \mathrm{m}$ and $3 \mu \mathrm{m}$ [40]. Observations of porosity on oxides formed in reactor are limited, possibly due to the difficulty in identifying porosity in the complex oxide microstructure formed under irradiation. However, Bossis et al. observed a small increase in intergranular porosity and grain decohesion away from the metal-oxide interface on irradiated oxides [27]. EIS 
measurements have also shown a reduction in barrier layer thickness on irradiated oxides when compared to non-irradiated oxides [28].

Due to the difficulties and expense involved with handling neutron-irradiated material, there has been a move towards using alternative forms of irradiation to mimic the effects of neutron irradiation. In-situ proton irradiation experiments have shown an enhancement of corrosion rate of $\sim 10$ times and significant changes to oxide grain morphology when compared with non-irradiated oxides [41]. Ex-situ proton irradiation of previously formed oxides has shown an increase in compressive stress in the oxide due to damage accumulation. Although the authors reported no major change to the oxide microstructure due to the irradiation, they claim that the proton irradiation improved the resistance of the oxide to deuterium diffusion [42]. It has also been shown that monoclinic $\mathrm{ZrO}_{2}$ can transform to the tetragonal phase under ion irradiation [43]-[46]. This transformation was also observed under neutron irradiation in pure $\mathrm{ZrO}_{2}$ with added impurities [47]. However, experimental evidence for increased tetragonal phase fractions in neutron irradiated commercial alloys is lacking [27].

In this study, automated crystal orientation mapping in the TEM is used to study the microstructure, phase and orientation of oxide films formed on Zircaloy-2 after 3 and 6 cycles in the Kernkraftwerk Leibstadt nuclear power plant (KKL), Switzerland. The effect of proton irradiation on oxide microstructure is also investigated using a preoxidised Zircaloy-2 sample proton irradiated to $\sim 5$ dpa. The use of automated crystal orientation mapping allows for relatively large areas of the oxide to be mapped with high spatial resolution [3], [16]. As a result, the microstructure is revealed in unprecedented detail, with simultaneous acquisition of phase and orientation information. In addition, high angle annular dark field scanning transmission electron 
microscopy (HAADF STEM) is used to observe cracking and porosity in the oxides. These detailed microstructural observations are then used to shed some light on the effect of irradiation on the well-known out-of-pile oxide growth processes, and thus the accelerated corrosion experienced by zirconium alloys in service.

\section{EXPERIMENTAL DETAILS}

\section{Materials Selection}

In this study a region of an oxide formed on recrystallised Zircaloy-2, supplied by Amec Foster Wheeler, was proton-irradiated at the Dalton Cumbrian Facility (DCF). Prior to irradiation, the specimen was exposed to $350{ }^{\circ} \mathrm{C}$ water with an elevated $\mathrm{pH}$ commensurate with typical pressurised water reactor (PWR) conditions for 55 days. For comparison to a non-irradiated condition and the post-oxidation proton irradiation experiment, a $3 \times 10 \times 20 \mathrm{~mm}$ bar was cut from the oxidised Zircaloy-2 sheet coupon. The thickness of the oxide after 55 days of exposure was estimated to be $1.9 \mu \mathrm{m}$ by weight gain using the relationship of $15 \mathrm{mg} / \mathrm{dm}^{2}$ for a $1 \mu \mathrm{m}$ oxide thickness [5]. Under these conditions, the Zircaloy-2 typically undergoes its first transition at $\sim 125$ days [48] and so this sample was assumed to be in the plateau region prior to the first transition. Oxides formed on Zircaloy-2 cladding material in the KKL boiling water reactor (BWR) reactor for 3 and 6 cycles were supplied by Westinghouse. The 3 and 6-cycle samples were of the Westinghouse designated LK3 and LK2 types respectively, the chemical compositions and heat treatments can be found in Refs [49][50]. The different heat treatments and chemical compositions result in different mean SPP diameters; $42 \mathrm{~nm}$ and $20 \mathrm{~nm}$ respectively in the non-irradiated LK3 [50] and LK2 [49] types. The details of the samples are shown in Table 1. The 3-cycle sample had formed an oxide thickness of $\sim 4 \mu \mathrm{m}$ after 3 power cycles in the reactor, it is therefore assumed to be within the accelerated region of in-reactor corrosion [21]. The 6-cycle sample had formed an oxide thickness of $\sim 108 \mu \mathrm{m}$ after 6 power cycles, 
which is at the upper end of the reported spread for Zircaloy-2 at a burnup of 50 $\mathrm{MWd} / \mathrm{kgU}$ [49], [51]. For neutron irradiated samples only the inner portion of the oxide was available for study, the oxide thickness that was available for each sample is shown in Table 1.

Table 1: Irradiated material used in this investigation from the KKL reactor in Switzerland. Approximate dpa was estimated from the burnup using the relationship $\sim 3.2 \mathrm{MWd} / \mathrm{kgU}$ per dpa from [52].

\begin{tabular}{ccccccc}
\hline Material & $\begin{array}{c}\text { Thermal } \\
\text { Treatment }\end{array}$ & $\begin{array}{c}\text { Burnup } \\
(\mathrm{MWd} / \mathrm{kgU})\end{array}$ & Cycles & $\begin{array}{c}\text { Approximate } \\
\text { dpa }\end{array}$ & $\begin{array}{c}\text { Original oxide } \\
\text { thickness } / \mu \mathrm{m}\end{array}$ & $\begin{array}{c}\text { Oxide thickness after } \\
\text { Preparation } / \mu \mathrm{m}\end{array}$ \\
\hline \hline & & & & & & \\
Zircaloy-2 & LK3 & 35 & 3 & 11 & 4 & 2.7 \\
Zircaloy-2 & LK2 & 50 & 6 & 16 & 108 & 4.2 \\
\hline
\end{tabular}

\section{Proton irradiation}

Proton-irradiation was performed using the $5 \mathrm{meV}$ NEC 15SDH-4 Pelletron Tandem Ion Accelerator at the Dalton Cumbrian Facility (DCF). DCF is a state-of-the-art facility that has the capability of inducing radiation damage via proton and heavy ion irradiation [53]. The proton irradiation took place on the material damage beamline using a custom-made rig allowing for the in-vacuum irradiation of solid materials [54]. The irradiation was confined to an area of $10 \times 6 \mathrm{~mm}$ on the largest face of the bar using a tantalum aperture, allowing for direct comparison with a non-irradiated area on the same sample. The area was irradiated at a temperature of $\sim 350^{\circ} \mathrm{C}$ with 1.5 $\mathrm{MeV}$ protons. An average current of $\sim 30 \mu \mathrm{A}$ was measured directly on the sample over the 96 hours of exposure. The damage profile, as calculated by SRIM [55], is shown in Figure 1. The predicted level was calculated to be $\sim 5$ dpa at $60 \%$ depth with the damage level in the oxide being 2dpa. The "quick" Kinchin and Pease SRIM calculation method was used, as recommended by Stoller et al. for direct comparison between ion and neutron irradiation [56].

\section{Sample preparation for TEM}


The neutron-irradiated samples were prepared from bulk cladding samples by Studsvik using the in-situ focused ion beam (FIB) lift out technique [57]. A protective layer of Pt was applied to the samples prior to lift-out to protect the oxide from FIB damage. $\sim 2 \mu \mathrm{m}$ thick lamella were then prepared from the inner region of the oxide near the metal-oxide interface and shipped to the University of Manchester for further thinning. The samples were thinned using $\mathrm{Ga}^{+}$ions at $30 \mathrm{keV}$ with an FEI Quanta 3D dual beam FIB. After thinning, cleaning of the samples was performed at $5 \mathrm{keV}$ and 2 $\mathrm{keV}$ to remove surface FIB damage. The reference and proton irradiated lamella were prepared from the bulk coupon using the same method. The FIB technique is particularly suited for preparation of cross sectional samples from insulating oxide films on a substrate, where traditional TEM sample preparation methods such as electropolishing are not applicable.

\section{Transmission Electron Microscopy}

\section{Chemical mapping}

Due to the complex nanostructure in zirconium oxide films, the samples were required to be extremely thin $(<100 \mathrm{~nm})$ in order to undertake reliable diffraction analysis. Thinning to the required thickness in the region of interest (near the metaloxide interface) resulted in the loss of the top portion of the oxide for some samples during preparation, as shown in Figure 2. The loss of this top layer, as well as its associated platinum coating, resulted in direct exposure of the remaining oxide to the ion beam. Ion implantation from the FIB has been shown to alter the microstructure of materials inducing phase transformations [58]. As such, high-resolution chemical mapping was performed on FIB samples to identify sites of $\mathrm{Ga}^{+}$implantation which could interfere with analysis of the oxide, as will be discussed later. Chemical mapping was performed using FEI Talos F200X TEM operating at $200 \mathrm{keV}$ with a probe current of $120 \mathrm{pA}$. The use of an FEI ChemiSTEM ${ }^{\mathrm{TM}}$ system, which consists of 
four windowless EDS detectors in close proximity to the sample, gives a collection angle of $0.9 \mathrm{sr}$ and enables ultra-high resolution, high sensitivity chemical mapping.

\section{Automated crystal orientation mapping in TEM}

Automated crystal orientation mapping was performed using an FEI Tecnai F30 FEGTEM operating at $300 \mathrm{keV}$. In order to provide a small, parallel probe on the sample surface, a $20 \mu \mathrm{m}$ condenser aperture was used, giving a probe diameter of $\sim 3 \mathrm{~nm}$. Beam scanning, pattern collection and post processing were carried out using the ASTAR automated crystal mapping system [59]. The mapping was carried out by scanning the beam across the sample using a $5 \mathrm{~nm}$ step size and recording diffraction patterns using an external CCD camera allowing for a fast acquisition rate. In order to reduce dynamical effects and increase the number of visible reflections, the beam is precessed at an angle of $0.4^{\circ}$. This precession angle has previously been shown to provide an optimal balance between spatial resolution and pattern quality for $\mathrm{ZrO}_{2}$ films [60]. The archived patterns are processed offline using the ASTAR template matching software developed by Rauch et al. [61]. This technique uses image correlation to match the recorded patterns with theoretical templates generated for a finite number of orientations from each known phase in the material. Each pattern is assigned a solution based on the best match with the phase/orientation among the bank of templates, as determined by the correlation index. Example patterns and corresponding solutions are shown in Figure 3. In case of overlapping patterns, such as at a grain boundary, the index correlation will be low and as such index maps can be used to reveal the grain structure in oxide films in great detail. Furthermore, in order to assess the quality of the solution, each matched pattern is given a reliability index, which is calculated using the ratio of the two best-matched solutions. For orientation and phase analysis, a reliability threshold of 10 was used, which has previously been shown to be adequate for assessment of the accuracy of template 
matching in monoclinic $\mathrm{ZrO}_{2}$ [60]. Phase maps are therefore overlayed with grayscale reliability maps so that non-reliable solutions will appear darker. It should be noted that a reliability filter was not used for calculating misorientation angle distributions, as this dramatically decreases the number of boundaries available for analysis and also may bias the results towards boundaries between larger grains. As this investigation is focused on microstructure of the oxide, hydrides and suboxide phases were not included in the analysis. This increases the reliability of phase identification in the oxide region and also reduces analysis time.

\section{Porosity investigation}

Porosity in zirconium oxide films is usually imaged using Fresnel contrast in the TEM [10], [13], [31]. However, due to the difficulties in identifying porosity in irradiated oxides using Fresnel contrast, high angle annular dark field scanning transmission electron microscopy (HAADF STEM) was employed in this study. The reduced diffraction contrast in this mode allows for identification of nanopores without interference from the complex microstructure and high damage levels induced by irradiation. As the spatial resolution of the technique is limited by sample thickness, extremely thin samples are required in order to resolve nanoporosity. This technique has previously been used for quantitative analysis of nanoporosity in LZO oxide thin films [62]. HAADF STEM imaging was performed on the FEI Tecnai F30 FEG-TEM operating at $300 \mathrm{keV}$ with a $50 \mu \mathrm{m}$ condenser aperture giving a probe convergence angle of $12 \mathrm{mrad}$. A camera length of $250 \mathrm{~mm}$ was used to provide enhanced $\mathrm{Z}$ contrast. As the effects of diffraction contrast are reduced in HAADF images, it makes them suitable for tomographic reconstruction [63]. In order to identify the 3dimensional distribution of the porosity, HAADF-STEM tomography was performed with tilt angles from $-45^{\circ}$ to $44^{\circ}$. Alignment was performed using cross-correlation and patch tracking in IMOD [64] and reconstruction undertaken using a SIRT 
algorithm with 10 iterations in the 3D software package [65]. The limited tilt angle range of the tilt series results in 'missing wedge' artefacts that act to elongate features in the z-direction (the direction of the beam at $0^{\circ}$ sample tilt). The missing wedge artefact in this case limits the precise determination of the shape of pores in the sample.

\section{RESULTS}

\section{Chemical mapping in TEM}

Figure 4(a) shows a chemical map of the top edge of a FIB sample, prepared from the autoclave oxide without irradiation. It shows a clear enrichment of $\mathrm{Ga}^{+}$ions following the topography of the top surface. The concentration of $\mathrm{Ga}^{+}$ions ranged from $\sim 4$ at $\%$ at the outer surface to $\sim 1$ at $\% 60 \mu \mathrm{m}$ into the oxide. No other chemical enrichment was observed in this region. In order to investigate this further, automated crystal orientation mapping in the TEM was also performed in the same region of oxide, as shown in Figure 4(b). A continuous region of tetragonal grains is observed on the top surface, coinciding directly with the $\mathrm{Ga}^{+}$implantation. This feature was observed on the majority of oxide samples when the protective Pt layer is eroded during thinning, regardless of position in the oxide, and so it is thought that the implantation of ions is inducing transformation from monoclinic to tetragonal. However, $\mathrm{Ga}^{+}$implantation was not observed elsewhere in the samples, provided that the ion beam is at a glancing angle to the sample surface. It therefore appears that the level of implantation is dependent on the angle of incidence with respect to the sample surface. This gives us confidence that grains indexed as tetragonal away from the top surface were likely to have existed in the bulk oxide prior to sample preparation. This top layer of tetragonal grains is not included in any of the subsequent phase fraction calculations. 


\section{Automated crystal orientation mapping in TEM}

\section{Autoclave formed oxide without irradiation}

The correlation index map for the oxide formed in the autoclave without irradiation, Figure 5(a), provides an overview of the grain morphology in the oxide. The oxide thickness in this region is $\sim 2 \mu \mathrm{m}$. Regions of the outer $\sim 300 \mathrm{~nm}$ of oxide, which is reported to consist of equiaxed grains [13][16], have been removed during sample preparation, as discussed previously. The majority of the remaining oxide is composed of columnar grains oriented towards the growth direction. The columnar grains are between $200-300 \mathrm{~nm}$ in length and $\sim 50 \mathrm{~nm}$ in width. The overlayed phase and reliability map of the autoclave oxide formed without irradiation is shown in Figure 5(b). It shows that the majority of the columnar oxide is monoclinic. There are regions of tetragonal grains distributed throughout the oxide layer. The small equiaxed tetragonal grains on the top edge of the sample are correlated with $\mathrm{Ga}^{+}$ implantation from sample preparation, as previously discussed, and so are not included in tetragonal phase fraction calculations. The reliably indexed tetragonal phase fraction of the autoclave-formed oxide, without proton irradiation, was estimated to be $\sim 3 \%$. The orientation map for this sample is shown in Figure 6(a). The grains are coloured according to degrees away from the preferred fibre texture component, as shown in the legend in Figure 6(e). The main texture component for this oxide was observed to be a $(10 \overline{2})$ fibre, which is a slight deviation from the usual $(10 \overline{3})-(10 \overline{5})$ texture observed in oxides formed in other alloys [3], [6]-[9]. However, it can be seen that the majority of the oxide is composed of columnar grains with the $(10 \overline{2})$ planes parallel to the metal-oxide interface, as indicated by the large, relatively sharp peak in the distribution around 0 degrees deviation from this main fibre component (Figure 6(e)).

\section{Proton irradiated autoclave formed oxide}


The correlation index map for the proton-irradiated region of the autoclave-formed oxide is shown in Figure 5(c). The majority of the oxide is composed of columnar monoclinic grains, similar to the non-irradiated region. These grains are mostly oriented so their long direction is perpendicular to the undulating interface. There is a band of equiaxed grains on the outer surface of the oxide, about $200 \mathrm{~nm}$ in width. A second phase particle (SPP) of diameter $\sim 150 \mathrm{~nm}$ is observed in the oxide, indexed as a $\mathrm{Zr}(\mathrm{Fe}, \mathrm{Cr})_{2}$ type particle. A higher magnification image of the indexed SPP, and corresponding diffraction patterns, is shown in Figure 7. The diffraction patterns show amorphisation of the particle towards the outer oxide. A large crack is located directly above the SPP, which is correlated to a delayed oxidation front agreeing with previous observations on this alloy [66]. The phase map in Figure 5(d) shows a significant change in the amount of tetragonal after proton-irradiation, with an increase from $\sim 3 \%$ in the non-irradiated case to $\sim 8 \%$. Compared to the nonirradiated oxide, the tetragonal grains appear larger, with a larger concentration at the metal-oxide interface. The orientation map (Figure 6(b)) and corresponding legend ((Figure 6(f)) show a weaker texture in this proton irradiated region of the oxide. However, this is likely due to the undulations of the interface, therefore spreading the observed texture with respect to the external reference frame. Again, this map is coloured according to degrees away from the $(10 \overline{2})$ fibre texture.

\section{Oxide formed in reactor -3 cycles}

The index map for the oxide formed after 3 cycles in reactor is shown in Figure 5(e). It should be emphasised that this sample only represents the metal oxide interface region of a thicker sample. The index map shows a more irregular grain morphology than the autoclave-formed oxide. There also appears to be a complex grain structure towards the interface. The phase map in Figure 5(f) shows a concentration of tetragonal grains towards the metal-oxide interface is correlated to this region of 
complex grain morphology. The reliably indexed tetragonal phase fraction was calculated to be $\sim 3 \%$ for this sample. The monoclinic grains are generally equiaxed and are estimated to be $\sim 100-200 \mathrm{~nm}$ in diameter, although there is a lot of variation in both size and shape. The orientation map (coloured as deviation from $(10 \overline{2})$ fibre component) for this sample is shown in Figure 6(c) and shows a more heterogeneous orientation distribution in the oxide formed in reactor. There appear to be clusters of similar orientations, with large regions of irregular shaped grains oriented away from the preferred texture component.

\section{Oxide formed in reactor -6 cycles}

The index map, shown in Figure 5(g), shows a finer grain structure in the oxide formed after 6 cycles in reactor when compared to the 3-cycle oxide. Although it should be noted that due to this alloy being of the LK2 type, while the 3-cycle sample was of the LK3 type, the differences cannot be solely attributed to the time in-reactor as the SPP size distribution has been shown to be an important factor in the corrosion process of Zircaloy-2 [66]. The microstructure consists mainly of equiaxed grains, of diameter 50-100 $\mathrm{nm}$, some of which are elongated in the growth direction. The equiaxed grains are smaller than the other oxides in this investigation and columnar grain growth is much less extensive than in the non-irradiated oxide. The phase map, shown in Figure 5(h) shows that the tetragonal phase fraction is lower than in the other oxides in this investigation. The tetragonal phase fraction was $\sim 1 \%$, with the majority distributed towards the metal-oxide interface. The interfacial tetragonal grains observed on the other samples were not visible in this sample. The $(10 \overline{2})$ orientation map for the 6-cycle oxide is shown in Figure 6(d). The map shows that a considerably weaker texture is formed on the 6-cycle oxide than the other oxides in this investigation, as demonstrated by the lower maximum intensity on the legend in Figure 6(h) and the large spread away from the main fibre component. As 
with the 3-cycle sample, the texture appears to be quite heterogeneous, with large clusters of orientations away from the preferred orientation.

\section{Porosity investigation}

Figure 8 shows a comparison of standard brightfield TEM imaging and HAADF STEM in a region of the 3-cycle oxide sample. Fresnel contrast in the overfocus image shows a line of intergranular porosity as dark regions with white fringes, in agreement with previous observations on non-irradiated oxides [10]. Due to the HAADF contrast being dependent largely on mass and thickness rather than diffraction contrast, the porosity becomes easier to identify and therefore more is visible in the HAADF image. Chemical mapping in these regions has revealed no chemical segregation to these features. It therefore seems that the Fresnel contrast technique is only able to detect certain regions of intergranular porosity, possibly due to the tilt of the grain boundary relative to electron beam. It is thought that the HAADF STEM technique is less sensitive to the orientation of the boundary. It is pointed out that as well as the intergranular porosity identified in Figure 8, there are also some other smaller dark features distributed homogenously across the sample.

Figure 9(a) and (b) show the type of isolated porosity that was observed in the autoclave-formed oxide without irradiation at different magnifications. Figure 9(a) was taken $\sim 1.5 \mu \mathrm{m}$ from the metal oxide interface, close to the top edge of the sample. Figure 9b) shows a higher magnification image of a small region of this oxide, identified by the box in Figure 9(a). The observed porosity was generally small and not interconnected and there was very little lateral cracking throughout the oxide. In comparison, extensive intergranular porosity was observed in the 3-cycle oxide, examples of which are shown in Figure 9(c) and (d). The images were taken approximately $2 \mu \mathrm{m}$ from the metal-oxide interface. The nanopores form continuous 
networks away from the metal-oxide interface, following the boundaries of the equiaxed grains. Although extensive away $(>1 \mu \mathrm{m})$ from the metal-oxide interface, this type of porosity was not visible closer to the interface. Similar to the autoclave formed oxide, there was very little lateral cracking in the 3-cycle sample.

The 3-dimensional nature of the pores in the 3-cycle oxide was investigated using HAADF STEM tomography. As the thickness of the sample increases rapidly with tilt angle, and to increase the tilt range, the tomography was performed on the outer edge of the sample, where the sample is thinnest. Figure 10 shows how the observed porosity changes as a function of tilt angle around a single equiaxed grain. It can be observed that the pores extend through the thickness of the FIB sample. The pores vary in size and although the largest pores are situated at the grain boundaries in the oxide, there are also some smaller intragranular pores observed. The intergranular pores appear to follow the 3D shape of the grain; this was observed on all grains in the analysed volume, although only one is shown here for clarity. In the 6-cycle oxide there was considerable decohesion between adjacent grains throughout the oxide, as shown in Figure 9(e) and (f), taken $\sim 1.2 \mu \mathrm{m}$ from the metal-oxide interface. In contrast to the 3-cycle oxide, this type of porosity was visible throughout the oxide. In addition, there was extensive lateral cracking through the entire oxide thickness, which was observed to have no periodicity. Although not shown here, there was no significant increase in cracking and nanoporosity observed in the autoclave formed oxide after proton irradiation.

\section{DISCUSSION}

\section{Tetragonal phase stability}

Before comparing the effects of irradiation on the microstructure development in the oxide, it is important to establish the extent to which FIB sample preparation has 
altered the microstructure from the bulk oxide. It has previously been observed that the relief of stress during FIB sample preparation can induce partial transformation of stress-stabilised tetragonal grains in zirconium oxide films [3], [12], [29], [40]. As a result the tetragonal phase fractions quoted in this study are significantly lower than observed using non-destructive techniques [12], [67]. The transformation has previously been shown to cause cracking and porosity in the oxide [13] and also lead to the creation of new twin boundaries [3], [17]. Care must therefore be taken when interpreting results from electron transparent oxide samples, as the observations may not directly represent the bulk oxide microstructure. Another important aspect to consider is the possibility of inducing transformation from ion implantation during sample preparation. Although there have been no previous studies showing an effect of FIB damage on tetragonal stabilisation in oxide corrosion films, a previous study has observed FIB-induced transformation of austenite in stainless steels [58]. Figure 4 shows clearly that an increased fraction of tetragonal grains is correlated with $\mathrm{Ga}^{+}$ implantation from the FIB. Importantly, $\mathrm{Ga}^{+}$implantation is only observed on the top surface of the FIB sample when the ion beam is approximately perpendicular to the sample surface and so any tetragonal grains observed away from this top edge are therefore likely to be a result of the corrosion process.

A significant increase in the tetragonal phase fraction was observed after proton irradiation. In contrast to the other oxides in this investigation, the tetragonal grains are larger and also distributed throughout the oxide. It therefore appears that the proton irradiation has stabilised tetragonal grains that formed during corrosion. However, it is also possible that the damage from the proton irradiation could have induced monoclinic-tetragonal transformation. Previous observations on bulk oxide sample have shown the development of a strong (001) texture in the tetragonal phase [8]. This is due to grains with these orientations having the smallest in-plane surface 
area, and consequently will reduce the compressive stress in the oxide. The (001) tetragonal pole figures, Figure 11, show a change in the preferred orientation of the tetragonal grains after proton irradiation. The tetragonal grains in the oxide before irradiation show a preferred orientation, with the (001) planes oriented approximately parallel to the metal-oxide interface. Although it should be noted that this is a very small number of tetragonal grains and therefore this texture is associated with a high degree of uncertainty. Figure 11(b) shows that the large tetragonal grains observed after proton irradiation appear to have a different texture. If these grains were formed during corrosion, it would be likely that they would be favorably oriented for growth, with the (001) planes oriented parallel to the interface. It is therefore possible that they were formed during proton irradiation, and not during oxide growth. This result is in agreement with non-destructive XRD examination by Simeone et al., who observed an increase in tetragonal phase fraction with increasing dpa under ion irradiation [45]. In addition, peak sharpening of the (101) tetragonal peak, observed using XRD after ion irradiation, has been linked to an increase in tetragonal grain size [68]. It is also interesting to point out that these large tetragonal grains are observed in the FIB sample even though the stresses have been relieved during sample preparation. These large tetragonal grains are located away from the metal-oxide interface, where the stress may be relaxed even in a bulk sample. It therefore appears that the proton irradiation is also allowing them to remain tetragonal without the stabilising effect of stress. However due to the high uncertainty in the texture measurement on the non-irradiated oxide, further non-destructive investigations are required to confirm that the protons are causing a transformation and not just stabilising pre-existing tetragonal grains.

The tetragonal phase fraction of the oxides formed in reactor was observed to be less than in the proton-irradiated oxide. In order to compare the effect of neutron and 
proton irradiation on the stability of the tetragonal phase, the dose experienced by the newly formed oxide near the metal-oxide interface studied here must be estimated. Uniform post-transition growth rates for BWR are estimated to be between 0.01 and $0.02 \mu \mathrm{m}$ a day [69]. If the onset of accelerated corrosion is assumed to occur at an oxide thickness of $\sim 2 \mu \mathrm{m}[21]$, then the $\sim 2 \mu \mathrm{m}$ of oxide closest to the interface had formed in $\sim 130$ days on the 3 -cycle sample. It is therefore estimated that this region of oxide had experienced a fraction of the total dose on this fuel rod (estimated to be $11 \mathrm{dpa}$ ), at 1-2 dpa. Due to the extremely fast corrosion rate on the 6-cycle sample, it is not possible to estimate the dose experienced by the metal-oxide interface region. However, it is likely to be significantly less than the 1- 2 dpa estimated for the 3-cycle sample despite the higher burnup. The regions close to the metal-oxide interface have therefore most likely experienced less damage than the proton-irradiated oxide. Thus, the trend of decreasing tetragonal phase fraction in the proton irradiated, 3-cycle and 6-cycle oxides seems to follow a decrease in dpa near the metal-oxide interface region. The mechanism of tetragonal stabilisation under irradiation is unclear, it is however possible that the displacement of $\mathrm{Zr}$ ions under irradiation could lead to the production of excess oxygen vacancies in the oxide, which have previously been shown cause tetragonal stabilisation [70][71].

Previous work has shown the formation of an extensive network of transformation twin boundaries in autoclave formed oxides [3], [16], [17]. These boundaries are thought to form as a result of the tetragonal-monoclinic transformation, whereby the formation of twin-related variants reduces the shear strain of the transformed region. Figure 12 shows the monoclinic misorientation distributions for the non-irradiated and reactor formed oxides. The distribution of boundaries is similar between the nonirradiated and neutron-irradiated samples, with a large proportion of $90^{\circ}$ and $180^{\circ}$ boundaries, which are characteristic twin boundaries resulting from tetragonal 
transformation [72]. The distribution of misorientations is similar, regardless of the difference in corrosion rate between the samples, thus indicating that the level of transformation that has occurred in the analysed regions of the oxides is similar. It has previously been suggested that the defects introduced by neutron irradiation will not be stable in the reactor environment, due to annealing of the defects at operating temperature [73]. It is therefore postulated that in the proton case, where the damage rate is $\sim 100$ times faster than during neutron irradiation, the defects are stable enough to allow stabilisation of the tetragonal phase. However, in the case of reactor-formed oxides it is likely that due to the slow damage rate, and the comparatively low dpa at the metal-oxide interface, the level of irradiation-induced stabilisation of tetragonal phase is not significant. This is especially important considering it is this interfacial region that is controlling the corrosion kinetics. Iron redistribution in irradiated oxides, through radiation-assisted dissolution of SPPs, has also been linked to localised tetragonal stabilisation [26]. No evidence of this type of stabilisation was observed in the reactor formed oxides in this investigation. Figure 7 shows a region of tetragonal grains in the immediate vicinity of the SPP embedded in the autoclave oxide after proton irradiation. However, it is likely that Fe redistribution is less severe in the autoclave oxide after proton irradiation and therefore the stabilisation of this region is probably due to the defects introduced by the irradiation. It appears that the amount of remaining tetragonal grains and fraction of transformation twin boundaries are similar between the non-irradiated and reactor-formed oxides and so it is likely that there are other mechanisms controlling the accelerated corrosion under reactor conditions.

\section{Oxide microstructure}

One of the major differences between the non-irradiated oxide and oxides formed in reactor is the grain morphology. The current work shows that the irradiated oxides 
have a more heterogeneous microstructure, with irregular grain morphology and a higher fraction of equiaxed grains. It is difficult to ascertain whether this change in grain morphology is a cause or consequence of the accelerated corrosion. An increased oxygen diffusion rate through the oxide under irradiation could lead to enhanced nucleation at the interface and the development of a more equiaxed, irregular grain structure. This enhanced nucleation rate would also cause a reduction in the growth of well-oriented columnar grains, resulting in the overall weakening of texture observed here with increasing levels of burnup. There are many possible reasons for an increased diffusion rate when the oxide is formed under irradiation. Verlet et al. showed the presence of irradiation defects, such as vacancies, in a preexisting oxide after light ion irradiation using Raman spectroscopy [73]. It is clear that irradiation defects will increase the mobility of charged species in the oxide and therefore increase the oxidation rate. Of course, in the real reactor situation the conductivity of the oxide will be further increased by the effect of $\gamma$ flux (RIC) [74]. Dislocation loops have been observed in stabilised cubic $\mathrm{ZrO}_{2}$ after electron [75] and neutron irradiation [76]. The formation and accumulation of damage clusters into extended lattice defects was also observed in the same material [44]. However evidence for significant accumulation of irradiation defects in zirconium oxide corrosion films is lacking. It is therefore likely, as discussed previously, that the defects are not stable in the oxide and it has been suggested that they are preferentially eliminated at grain boundaries in the oxide of which there are plenty due to the nanosized grains [29].

It is also important to discuss the evolution of the substrate microstructure under irradiation, as the metal substrate is likely to accumulate significantly more damage than the oxide in service. This in turn could affect the diffusion rate through the oxide under reactor conditions. Irradiation has been observed to lead to the formation of 
point defects in zirconium, resulting in the nucleation of a- and c-loops and the dissolution and amorphisation of SPPs in BWR conditions [77], [78]. Due to the wellknown protective role of SPPs in the corrosion process, the dissolution of SPPs during irradiation will undoubtedly have a detrimental impact on the protective character of reactor formed oxides. Due to the different SPP distribution achieved during LK2 and LK3 heat treatments, this dissolution of SPPs is likely to be more severe in the LK2 6cycle oxide, which shows a considerably faster corrosion rate and more disordered oxide microstructure than the LK3 3-cycle oxide. Another aspect of the substrate microstructure under irradiation that could be affecting the diffusion rate through the oxide is the formation of zirconium hydrides at the metal-oxide interface. Due to the heat flux in reactor conditions, hydrides will precipitate at the metal-oxide interface at high burn ups ( $>35 \mathrm{MWd} / \mathrm{kgU})$ [19]. The oxidation of this 'hydride rim' has previously been shown to result in accelerated corrosion in out-of-pile tests on hydrogen charged material [79] and so would likely contribute to the accelerated corrosion observed on the 6-cycle sample. It is also possible that the irradiation could be directly affecting the oxide nucleation and growth processes. Previous studies have shown the preferential nucleation of amorphous zirconia at the metal-oxide interface of irradiated oxides [24], [29]. It is postulated that the crystallisation of these amorphous regions during oxidation could result in disruption to the usual nucleation and growth processes and lead to the formation of randomly oriented nanocrystallites. However, no evidence of amorphous oxide phases was observed at the metal-oxide interface of the samples in this study.

As the burnup is increased, it is also likely that the loading regime of the cladding is changing. As the power is ramped up, pellet swelling leads to pellet-clad gap closure. The tensile stresses generated by this interaction can be relieved by creep in the cladding, leading to a significant reduction in stress after 3 cycles [80]. This is likely 
to result in a significant reduction in stress in the oxide. As the development of protective, well-oriented oxide grains has been linked to the role of compressive stress in the oxide, this reduction in stress could lead to the development of a more randomly oriented oxide. This could also affect the susceptibility of the oxide to the development of cracking and porosity.

\section{Porosity and cracking}

Significant differences in the amount and morphology of porosity have been observed between the non-irradiated and reactor-formed oxides. The HAADF STEM observations have shown the presence of significant levels of intergranular porosity after 3 cycles in the reactor. After 6 cycles, these pores appear to have coalesced and have resulted in significant decohesion between grains throughout the oxide. HAADF STEM tomography has revealed the 3-dimensional distribution of these pores. The pores seem to surround the equiaxed grains, providing easy percolation paths for diffusing species. It has been suggested that porosity in growing oxides can result from deformation mechanisms under compressive stress, specifically by a combination of diffusional creep and grain-boundary sliding [81]. The presence of irradiation defects in the oxide would enhance the creep diffusion mechanisms; in addition an increased vacancy concentration at oxide grain boundaries could enhance pore formation during grain boundary sliding. This mechanism could therefore provide an explanation for the increased amount of porosity observed in the oxides with increasing burnup. It is also possible that the diffusion of alloying elements away from oxide grain boundaries and the subsequent build up of vacancies could contribute to the formation of porosity [82]. Due to enhanced SPP dissolution in the metal under irradiation, the enrichment of alloying elements at oxide grain boundaries (already observed in non-irradiated oxides [83]) is likely to be more severe in reactor formed oxides, resulting in a steeper concentration gradient and thus more vacancy 
migration. From out-of-pile observations, it has been shown that the transformation from tetragonal to monoclinic $\mathrm{ZrO}_{2}$ could lead to the formation of intergranular porosity in zirconium oxide films [27], [84]. However, the differences in porosity observed here cannot be correlated to an increased level of transformation, as similar tetragonal phase and monoclinic twin boundary fractions are observed in the nonirradiated and reactor formed oxides.

Figures 5 and 6 show a clear reduction in well-oriented columnar grain growth with increasing burnup, which correlates with the increasing levels of intergranular porosity. Out-of-reactor observations have shown that regions of oxide with more well-oriented, large columnar grain growth exhibit less cracking and porosity [5][39] and so it is likely that the coherent grain boundaries that form between these types of grains are more protective against porosity. It therefore appears that the modified nucleation and growth processes in-reactor, resulting in a more equiaxed, disordered oxide microstructure, could allow for more intergranular porosity to form and therefore result in the accelerated corrosion experienced under reactor conditions.

\section{CONCLUSIONS}

In this study, state-of-the-art TEM techniques have been used to show a clear evolution of oxide microstructure and porosity formed on Zircaloy-2 in a BWR reactor. These observations are then compared to an autoclave formed oxide before and after proton irradiation. The conclusions are as follows:

- Proton irradiation of an existing oxide was observed to cause stabilisation of the tetragonal phase. In contrast the reactor-formed oxides did not show increased levels of tetragonal phase most likely due to the low damage rate and low dose at the metal-oxide interface. 
- A more heterogeneous microstructure was observed in the reactor formed oxides with reduced columnar grain growth.

- A weaker oxide texture was observed to form with increasing burnup, which correlated with increased levels of intergranular porosity and grain decohesion.

- According to our observations, the accelerated corrosion experienced under reactor conditions cannot be attributed to the transformation of metastable tetragonal grains.

- It is suggested that the usual out-of-reactor oxide nucleation and growth processes are modified under reactor conditions, leading to a reduction in well-oriented columnar grain growth which in turn leads to the development of extensive intergranular porosity.

\section{ACKNOWLEDGMENTS}

This research was supported by the Engineering and Physical Sciences Research Council UK (EPSRC) through the Centre for Doctoral Training in Advanced Metallic Systems (research code: EP/G036950/1). This research was also part funded by the EPSRC PACIFIC "Providing a Nuclear Fuel Cycle in the UK for Implementing Carbon Reductions" grant (research code: EP/L018616/1). The authors gratefully acknowledge the industrial support on this project from Rolls Royce, Amec Foster Wheeler, Westinghouse and Studsvik. Also the authors would like to thank Mark Fenwick and Michael Waters at Amec Foster Wheeler for carrying out the corrosion testing and Antoine Ambard from EDF for technical discussions during the writing of this paper. 


\section{REFERENCES}

[1] J. Bryner, 'The Cyclic nature of Corrosion of Zircaloy-4 in $633 \mathrm{~K}$ Water', $J$. Nucl. Mater., vol. 82, pp. 84-101, 1979.

[2] E. Hillner, D. G. Franklin, and J. D. Smee, 'Long-term corrosion of Zircaloy before and after irradiation', J. Nucl. Mater., vol. 278, no. 2, pp. 334-345, 2000 .

[3] A. Garner, A. Gholinia, P. Frankel, M. Gass, I. MacLaren, and M. Preuss, 'The microstructure and microtexture of zirconium oxide films studied by transmission electron backscatter diffraction and automated crystal orientation mapping with transmission electron microscopy', Acta Mater., vol. 80, pp. 159-171, 2014.

[4] A. T. Motta, A. Yilmazbayhan, R. J. Comstock, J. Partezana, G. P. Sabol, B. Lai, and Z. Cai, 'Microstructure and Growth Mechanism of Oxide Layers Formed on $\mathrm{Zr}$ Alloys Studied with Micro-Beam Synchrotron Radiation', in Zirconium in the Nuclear Industry: 14th International Symposium. ASTM STP 1467, 2005, vol. 2, no. 5, pp. 205-232.

[5] A. Yilmazbayhan, E. Breval, A. T. Motta, and R. J. Comstock, 'Transmission electron microscopy examination of oxide layers formed on $\mathrm{Zr}$ alloys', $J$. Nucl. Mater., vol. 349, no. 3, pp. 265-281, Mar. 2006.

[6] J. Lin, H. Li, and J. A. Szpunar, 'Analysis of zirconium oxide formed during oxidation at $623 \mathrm{~K}$ on $\mathrm{Zr}-2.5 \mathrm{Nb}$ and Zircaloy-4', Mater. Sci. Eng. A, vol. 381, no. 1-2, pp. 104-112, Sep. 2004.

[7] A. Garner, M. Preuss, and P. Frankel, 'A method for accurate texture determination of thin oxide films by glancing angle laboratory X-ray diffraction', J. Appl. Crystallogr., vol. 47, pp. 575-583, 2014.

[8] J. Lin, 'Effect of Texture and Microstructure of Zirconium Alloys on their Oxidation and Oxide Texture', McGill University, Montreal, Canada, 2005.

[9] H. Li, M. Glavicic, and J. A. Szpunar, 'A model of texture formation in $\mathrm{ZrO} 2$ films’, Mater. Sci. Eng. A, vol. 366, no. 1, pp. 164-174, Feb. 2004.

[10] N. Ni, S. Lozano-Perez, M. . Jenkins, C. English, G. D. . Smith, J. . Sykes, and C. R. . Grovenor, 'Porosity in oxides on zirconium fuel cladding alloys, and its importance in controlling oxidation rates', Scr. Mater., vol. 62, no. 8, pp. 564567, Apr. 2010.

[11] P. Bossis, G. Lelikvre, P. Barberis, X. Iltis, and F. Lefebvre, 'Multi-Scale Characterization of the Metal-Oxide Interface of Zirconium Alloys', in Zirconium in the Nuclear Industry: 12th International Symposium, ASTM STP 1354, 2000, pp. 918-945.

[12] J. Godlewski, J. . Gros, M. Lambertin, J. . Wadier, and H. Weidinger, 'Raman Spectroscopy Study of the Tetragonal-to-Monoclinic Transition in Zirconium Oxide Scales and Determination of Overall Oxygen Diffusion by Nuclear Analysis of $\mathrm{O}(18)$ ', in Zirconium in the Nuclear Industry: 9th International Symposium. ASTM STP 1132, 1991, pp. 416-436.

[13] M. Preuss, P. Frankel, S. Lozano-Perez, D. Hudson, E. Polatidis, N. Ni, and J. Wei, 'Studies Regarding Corrosion Mechanisms in Zirconium Alloys', in 
Zirconium in the Nuclear Industry - 16th International Symposium. ASTM STP 1529, 2011, vol. 8, no. 9, pp. 1-23.

[14] E. Polatidis, P. Frankel, J. Wei, M. Klaus, R. J. Comstock, A. Ambard, S. Lyon, R. Cottis, and M. Preuss, 'Residual stresses and tetragonal phase fraction characterisation of corrosion tested Zircaloy-4 using energy dispersive synchrotron X-ray diffraction', J. Nucl. Mater., vol. 432, no. 1-3, pp. 102-112, Jan. 2013.

[15] J. Wei, P. Frankel, E. Polatidis, M. Blat, A. Ambard, R. . J. Comstock, L. Hallstadius, and M. Preuss, 'The effect of $\mathrm{Sn}$ on autoclave corrosion performance and corrosion mechanisms in $\mathrm{Zr}-\mathrm{Sn}-\mathrm{Nb}$ alloys', Acta Mater., vol. 61, no. 11, pp. 4200-4214, 2013.

[16] A. Garner, J. Hu, A. Harte, P. Frankel, C. Grovenor, S. Lozano-Perez, and M. Preuss, 'The effect of Sn concentration on oxide texture and microstructure formation in zirconium alloys', Acta Mater., vol. 99, pp. 259-272, 2015.

[17] V. Y. Gertsman, Y. P. Lin, A. P. Zhilyaev, and J. A. Szpunar, 'Special grain boundaries in zirconia corrosion films', Philos. Mag. A, vol. 79, no. 7, pp. 1567-1590, 1999.

[18] F. Garzarolli, Y. Broy, and R. A. Busch, 'Comparison of the Long-Time Corrosion Behavior of Certain Zr Alloys in PWR, BWR, and Laboratory Tests', in Zirconium in the Nuclear Industry: 11th International Symposium, ASTM STP 1295, 1996, pp. 850-864.

[19] P. Bossis, D. Pecheur, K. Hanifi, J. Thomazet, and M. Blat, 'Comparison of the High Burn-Up Corrosion on M5 and Low Tin Zircaloy-4', Zircon. Nucl. Ind. 14th Int. Symp. ASTM STP 1467, pp. 494-525, 2006.

[20] A. M. Garde, S. R. Pati, M. A. Krammen, G. P. Smith, and R. K. Endter, 'Corrosion Behavior of Zircaloy-4 Cladding with Varying Tin Content in High- Temperature Pressurized Water Reactors', in Zirconium in the Nuclear Industry: 10th International Symposium, ASTM STP 1245, 1994, pp. 760-778.

[21] E. Hillner, 'Long-Term In-Reactor Corrosion and Hydriding of Zircaloy-2 Tubing', in Zirconium in the Nuclear Industry: 5th International Symposium ASTM STP 754, 1982, pp. 450-478.

[22] Y. Etoh, S. Shimada, T. Yasuda, T. Ikeda, R. B. Adamson, J. S. Fred Chen, Y. Ishii, and K. Takei, 'Development of New Zirconium Alloys for a BWR', in Zirconium in the Nuclear Industry: 11th International Symposium, ASTM STP 1295, 1996, pp. 825-849.

[23] B. Cheng, R. M. Kruger, and R. B. Adamson, 'Corrosion Behavior of Irradiated Zircaloy', in Zirconium in the Nuclear Industry: 10th International Symposium, ASTM STP 1245, 1994, pp. 400-418.

[24] X. Iltis, F. Lefebvre, and C. Lemaignan, 'Microstructure Evolutions and Iron Redistribution in Zircaloy Oxide Layers: Comparative Effects of Neutron Irradiation Flux and Irradiation Damages', in Zirconium in the Nuclear Industry: 11th International Symposium, ASTM STP 1295, 1996, pp. 242-264.

[25] F. Lefebvre and C. Lemaignan, 'Irradiation effects on corrosion of zirconium alloy claddings', J. Nucl. Mater., vol. 248, pp. 268-274, 1997. 
[26] X. Iltis, F. Lefebvre, and C. Lemaignan, 'Microstructural study of oxide layers formed on Zircaloy-4 in autoclave and in reactor Part II : Impact of the chemical evolution of intermetallic precipitates on their zirconia environment', J. Nucl. Mater., vol. 224, pp. 121-130, 1995.

[27] P. Bossis, J. Thomazet, and F. Lefebvre, 'Study of the Mechanisms Controlling the Oxide Growth Under Irradiation: Characterization of Irradiated Zircaloy-4 and Zr-INb-O Oxide Scales', in Zirconium in the Nuclear Industry: 13th International Symposium, ASTM STP 1423, 2002, pp. 190-221.

[28] O. Gebhardt, A. Hermann, G. Bart, H. Blank, F. Garzarolli, and I. F. L. Ray, 'Investigation of In-Pile Grown Corrosion Films on Zirconium-Based Alloys', in Zirconium in the Nuclear Industry: 11th International Symposium, ASTM STP 1295, 1996, pp. 218-241.

[29] X. Iltis, F. Lefebvre, and C. Lemaignan, 'Microstructural study of oxide layers formed on Zircaloy-4 in autoclave and in reactor Part I: Impact of irradiation on the microstructure of the zirconia layer', J. Nucl. Mater., vol. 224, pp. 109$120,1995$.

[30] S. Abolhassani, R. Restani, T. Rebac, F. Groeschel, W. Hoffelner, G. Bart, W. Goll, and A. F, 'TEM Examinations of the Metal-Oxide Interface of Zirconium Based Alloys Irradiated in a Pressurized Water Reactor', in Zirconium in the Nuclear Industry: 14th International Symposium, ASTM STP 1467, 2005, pp. 467-493.

[31] G. Sundell, M. Thuvander, and H.-O. Andrén, 'Barrier oxide chemistry and hydrogen pick-up mechanisms in zirconium alloys', Corros. Sci., vol. 102, pp. 490-502, 2016.

[32] B. D. Warr, M. B. Elmoselhi, S. B. Newcomb, N. S. McIntyre, A. M. Brennenstuhl, and P. C. Lichtenberger, 'Oxide Characteristics and Their Relationship to Hydrogen Uptake in Zirconium Alloys', in Zirconium in the Nuclear Industry: 9th International Symposium. ASTM STP 1132, 1991, pp. 740-757.

[33] R. A. Ploc, 'Mechanism of deuterium pickup in $\mathrm{Zr}-2.5 \mathrm{Nb}$ alloy', Mater. High Temp., vol. 17, no. 1, pp. 29-34, 2000.

[34] T. Kubo and M. Uno, 'Precipitate Behavior in Zircaloy-2 Oxide Films and Its Relevance to Corrosion Resistance', in Zirconium in the Nuclear Industry: 9th International Symposium, ASTM STP 1132, 1991, pp. 476-498.

[35] H. J. Beie, F. Mitwalsky, Alexander Garzarolli, H. Ruhmann, and H.-J. Sell, 'Examinations of the Corrosion Mechanism of Zirconium Alloys', in Zirconium in the Nuclear Industry: 10th International Symposium, ASTM STP 1245, 1994, pp. 615-643.

[36] H. Anada and K. Takeda, 'Microstructure of Oxides on Zircaloy-4, $1.0 \mathrm{Nb}$ Zircaloy-4, and Zircaloy-2 Formed in 10.3-MPa Steam at 673 K', Zircon. Nucl. Ind. 11th Int. Symp. ASTM STP 1295, pp. 35-54, 1996.

[37] G. P. Sabol, S. G. McDonald, and G. P. Airey, 'Microstructure of the Oxide Films Formed on Zirconium-Based Alloys', in Zirconium in Nuclear Applications, ASTM STP 551., 1974, pp. 435-448.

[38] A. W. Urquhart and D. A. Vermilyea, 'Characterisation of Zircaloy Oxidation 
Films', in Zirconium in Nuclear Applications, ASTM STP 551, 1974, pp. 463478.

[39] B. Wadman, Z. Lai, H. O. Andren, A. L. Nystrom, P. Rudling, and H. Pettersson, 'Microstructure of Oxide Layers Formed During Autoclave Testing of Zirconium Alloys', in Zirconium in the Nuclear Industry: 10th International Symposium, ASTM STP 1245, 1994, pp. 579-598.

[40] F. Garzarolli, H. Seidel, R. Tricot, and J. . Gros, 'Oxide Growth Mechanism on Zirconium Alloys', in Zirconium in the Nuclear Industry: 9th International Symposium, ASTM STP 1132., 1991, pp. 395-415.

[41] P. Wang and G. S. Was, 'Oxidation of Zircaloy-4 during in situ proton irradiation and corrosion in PWR primary water', J. Mater. Res., vol. 30, no. 9, pp. 1335-1348, 2015.

[42] K. Une, I. Takagi, K. Sawada, H. Watanabe, K. Sakamoto, and M. Aomi, 'Effect of proton irradiation on deuterium diffusion in zirconium oxide layer', J. Nucl. Mater., vol. 420, no. 1-3, pp. 445-451, 2012.

[43] D. Simeone, J. L. Bechade, D. Gosset, a. Chevarier, P. Daniel, H. Pilliaire, and G. Baldinozzi, 'Investigation on the zirconia phase transition under irradiation', J. Nucl. Mater., vol. 281, no. 2-3, pp. 171-181, 2000.

[44] K. E. Sickafus, H. Matzke, T. Hartmann, K. Yasuda, J. A. Valdez, P. Chodak, M. Nastasi, and R. A. Verrall, 'Radiation damage effects in zirconia', J. Nucl. Mater., vol. 274, no. 1, pp. 66-77, 1999.

[45] D. Simeone, D. Gosset, J. L. Bechade, and A. Chevarier, 'Analysis of the monoclinic-tetragonal phase transition of zirconia under irradiation', J. Nucl. Mater., vol. 300, no. 1, pp. 27-38, 2002.

[46] C. Gibert-Mougel, F. Couvreur, J. M. Costantini, S. Bouffard, F. Levesque, S. Hémon, E. Paumier, and C. Dufour, 'Phase transformation of polycrystalline zirconia induced by swift heavy ion irradiation', J. Nucl. Mater., vol. 295, no. 1, pp. 121-125, 2001.

[47] J. Adam and B. Cox, 'Neutron and Fission Fragment Damage in Zirconia', Phys. Rev. Lett., vol. 3, no. 12, pp. 543-5442, 1959.

[48] B. Griggs, H. P. Maffei, and D. W. Shannon, 'Multiple Rate Transitions in the Aqueous Corrosion of Zircaloy', J. Electrochem. Soc., vol. 109, no. 8, p. 665, 1962.

[49] P. Tagtstrom, M. Limback, M. Dahlback, T. Andersson, and H. Pettersson, 'Effects of Hydrogen Pickup and Second- Phase Particle Dissolution on the InReactor Corrosion Performance of BWR Claddings', in Zirconium in the Nuclear Industry: 13th International Symposium, ASTM STP 1423, 2002, pp. 96-118.

[50] S. Valizadeh, G. Ledergerber, S. Abolhassani, D. Jadernas, M. Dahlbäck, M. E. V, G. Zhou, J. Wright, and L. Hallstadius, 'Effects of Secondary Phase Particle Dissolution on the In-Reactor Performance of BWR Cladding', J. ASTM Int., vol. 8, no. 2, 2011.

[51] P. Tejland, H. O. Andren, G. Sundell, M. Thuvander, B. Josegsson, L. Hallstadius, M. Ivermark, and M. Dahlback, 'Oxidation Mechanism in 
Zircaloy-2 - The Effect of SPP Size Distribution', in Zirconium in the Nuclear Industry: 17th International Symposium, ASTM STP 1543, 2015, pp. 373-403.

[52] V. N. Shishov, M. M. Peregud, A. V Nikulina, G. P. Kobylyansky, A. E. Novoselov, Z. E. Ostrovsky, and A. V Obukhov, 'Influence of structure phase state of $\mathrm{Nb}$ containing $\mathrm{Zr}$ alloys on irradiation-induced growth', J. ASTM Int., vol. 2, no. 8, pp. 666-685, 2005.

[53] L. Leay, W. Bower, G. Horne, P. Wady, A. Baidak, M. Pottinger, M. Nancekievill, A. D. Smith, S. Watson, P. R. Green, B. Lennox, J. A. Laverne, and S. M. Pimblott, 'Development of irradiation capabilities to address the challenges of the nuclear industry', Nucl. Instruments Methods Phys. Res. Sect. B Beam Interact. with Mater. Atoms, vol. 343, pp. 62-69, 2015.

[54] P. T. Wady, A. Draude, S. M. Shubeita, A. D. Smith, N. Mason, S. M. Pimblott, and E. Jimenez-Melero, 'Accelerated radiation damage test facility using a 5MV tandem ion accelerator', Nucl. Instruments Methods Phys. Res. Sect. A Accel. Spectrometers, Detect. Assoc. Equip., vol. 806, pp. 109-116, 2016.

[55] J. F. Ziegler and J. P. Biersack, 'Treatise on Heavy-Ion Science: Volume 6: Astrophysics, Chemistry, and Condensed Matter', D. A. Bromley, Ed. Boston, MA: Springer US, 1985, pp. 93-129.

[56] R. E. Stoller, M. B. Toloczko, G. S. Was, A. G. Certain, S. Dwaraknath, and F. A. Garner, 'On the use of SRIM for computing radiation damage exposure', Nucl. Instruments Methods Phys. Res. Sect. B Beam Interact. with Mater. Atoms, vol. 310, pp. 75-80, 2013.

[57] M. H. F. Overwijk, F. C. van den Heuvel, and C. W. T. Bulle-Lieuwma, 'Novel scheme for the preparation of transmission electron microscopy specimens with a focused ion beam', J. Vac. Sci. Technol. B Microelectron. Nanom. Struct., vol. 11, no. 6, p. 2021, 1993.

[58] K. E. Knipling, D. J. Rowenhorst, R. W. Fonda, and G. Spanos, 'Effects of focused ion beam milling on austenite stability in ferrous alloys', Mater. Charact., vol. 61, no. 1, pp. 1-6, 2010.

[59] E. F. Rauch and M. Véron, 'Automatic crystal orientation and phase mapping in TEM by precession diffraction', Microsc. Anal., vol. 22, pp. S5-S8, 2008.

[60] A. Garner, 'Investigating The Effect of Oxide Texture on the Corrosion Performance of Zirconium Alloys', The University of Manchester, 2015.

[61] E. F. Rauch and L. Dupuy, 'Rapid Spot Diffraction Patterns Identification through Template Matching', Arch. Metall. Mater., vol. 50, no. 1, pp. 8799rauch, 2005.

[62] E. Biermans, L. Molina, K. J. Batenburg, S. Bals, and G. Van Tendeloo, 'Measuring porosity at the nanoscale by quantitative electron tomography', Nano Lett., vol. 10, no. 12, pp. 5014-5019, 2010.

[63] P. A. Midgley and M. Weyland, '3D electron microscopy in the physical sciences: The development of Z-contrast and EFTEM tomography', Ultramicroscopy, vol. 96, no. 3-4, pp. 413-431, 2003.

[64] J. R. Kremer, D. N. Mastronarde, and J. R. McIntosh, 'Computer visualization 
of three-dimensional image data using IMOD.', J. Struct. Biol., vol. 116, no. 1, pp. 71-76, 1996.

[65] FEI, 'Inspect3D'. Hillsboro, Oregon, USA.

[66] P. Tejland, M. Thuvander, H. O. Andren, S. Ciurea, T. Andersson, M. Dahlback, and L. Hallstadius, 'Detailed Analysis of the Microstructure of the Metal/Oxide Interface Region in Zircaloy-2 after Autoclave Corrosion Testing', Zircon. Nucl. Ind. 16th Int. Symp. ASTM STP 1529, pp. 595-619, 2011.

[67] N. Petigny, P. Barberis, C. Lemaignan, V. Ch, and M. Lallemant, 'In situ XRD analysis of the oxide layers formed by oxidation at $743 \mathrm{~K}$ on Zircaloy 4 and Zr1NbO', J. Nucl. Mater., vol. 280, no. 3, pp. 318-330, Aug. 2000.

[68] F. Gibert, C. Couvreue, D. Damien, M. Gautier-Soyer, N. Thromat, M. J. Guittet, and S. Bouffard, 'Study of Irradiation Effects on the Crystallographic Nature of Zirconia', The International Nuclear Information System (INIS), 07Nov-2011. [Online].

Available: http://www.iaea.org/inis/collection/NCLCollectionStore/_Public/30/060/30060 381.pdf.

[69] V. F. Urbanic, B. Cox, and G. J. Field, 'Long-Term Corrosion and Deuterium Uptake in CANDU-PHW Pressure Tubes', in Zirconium in the Nuclear Industry - 7th International Symposium. ASTM STP 939., 1987, pp. 189-205.

[70] S. Fabris, A. T. Paxton, and M. W. Finnis, 'A stabilization mechanism of zirconia based on oxygen vacancies only', Acta Mater., vol. 50, pp. 51715178, 2002.

[71] P. Li, I. W. Chen, and J. E. Penner-hahn, 'Effect of Dopants on Zirconia Stabilization-An X-ray Absorption Study: I, Trivalent Dopants', J. Am. Ceram. Soc., vol. 77, no. 1, pp. 118-128, 1994.

[72] V. Y. Gertsman, A. P. Zhilyaev, and J. A. Szpunar, 'Near coincidence site lattice misorientations in monoclinic zirconia', Scr. Mater., vol. 35, no. 11, pp. 1247-1251, Dec. 1996.

[73] R. Verlet, M. Tupin, G. Baldacchino, K. Wolski, S. Miro, D. Gosset, K. Colas, M. Jublot, and F. Jomard, 'Influence of light ion irradiation of the oxide layer on the oxidation rate of Zircaloy-4', Corros. Sci., vol. 98, pp. 327-338, 2015.

[74] C. Lemaignan, 'Physical Phenomena Concerning Under Irradiation of $\mathrm{Zr}$ Alloys', in Zirconium in the Nuclear Industry: 13th International Symposium, ASTM STP 1423, 2002, pp. 20-29.

[75] B. Baufeld, D. Baither, U. Messerschmidt, M. Bartsch, and I. Merkel, 'In Situ Study on the Generation of Radiation Damage in Cubic-Zirconia in the HighVoltage Electron Microscope', J. Am. Ceram. Soc., vol. 76, no. 19441, pp. 3163-3166, 1993.

[76] F. W. Clinard, D. L. Rohr, and W. A. Ranken, 'Neutron-irradiation damage in stabilized ZrO2', J. Am. Ceram. Soc., vol. 60, no. 5-6, pp. 287-288, 1977.

[77] M. Griffiths, 'A review of microstructure evolution in zirconium alloys during irradiation', J. Nucl. Mater., vol. 159, no. C, pp. 190-218, 1988.

[78] R. W. Gilbert, M. Griffiths, and G. J. C. Carpenter, ‘Amorphous intermetallics 
in neutron irradiated zircaloys after high fluences', J. Nucl. Mater., vol. 135, no. 2-3, pp. 265-268, 1985.

[79] J. Wei, P. Frankel, M. Blat, A. Ambard, R. J. Comstock, L. Hallstadius, S. Lyon, R. A. Cottis, and M. Preuss, 'Autoclave study of zirconium alloys with and without hydride rim', Corros. Eng. Sci. Technol., vol. 47, no. 7, pp. 516$528,2012$.

[80] P. Bouffioux, J. Van Vliet, P. Deramaix, and M. Lippens, 'Potential causes of failures associated with power changes in LWR's', J. Nucl. Mater., vol. 87, no. 2-3, pp. 251-258, 1979.

[81] P. Kofstad, 'On the formation of porosity and microchannels in growing scales', Oxid. Met., vol. 24, no. 5-6, pp. 265-276, Dec. 1985.

[82] W. Gong, H. Zhang, C. Wu, H. Tian, and X. Wang, 'The role of alloying elements in the initiation of nanoscale porosity in oxide films formed on zirconium alloys', Corros. Sci., vol. 77, pp. 391-396, Dec. 2013.

[83] G. Sundell, M. Thuvander, and H.-O. Andrén, 'Enrichment of Fe and Ni at metal and oxide grain boundaries in corroded Zircaloy-2', Corros. Sci., vol. 65, pp. 10-12, Dec. 2012.

[84] P. Platt, P. Frankel, M. Gass, R. Howells, and M. Preuss, 'Finite element analysis of the tetragonal to monoclinic phase transformation during oxidation of zirconium alloys', J. Nucl. Mater., vol. 454, no. 1-3, pp. 290-297, 2014.

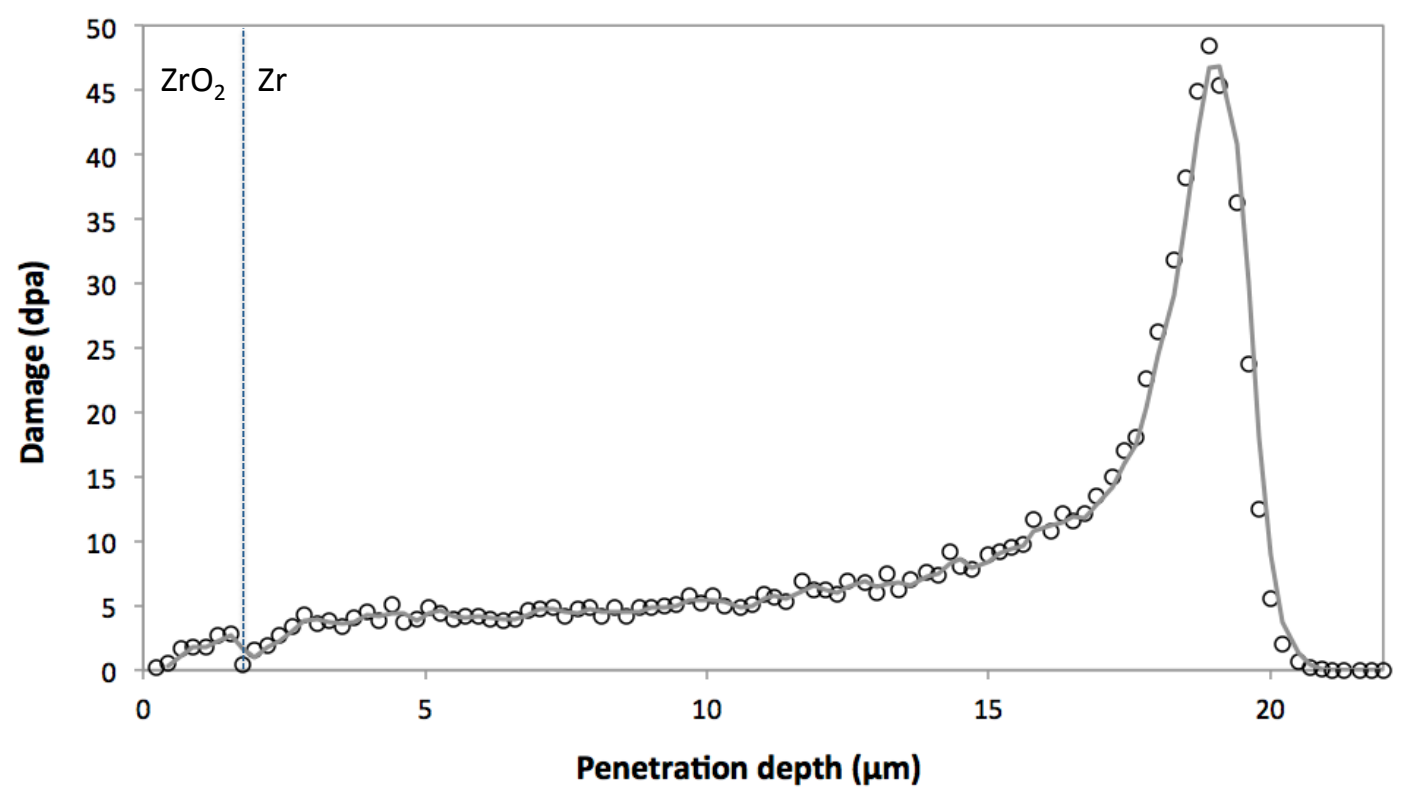

Figure 1: SRIM calculation showing damage profile in 1.8 $\mu \mathrm{m} \mathrm{ZrO}_{2}$ film on pure $\mathrm{Zr}$ substrate by $\mathrm{H}^{+}$ion irradiation at $1.5 \mathrm{MeV}$, with an average current of $30 \mu \mathrm{A}$ over 96 hours of exposure. 


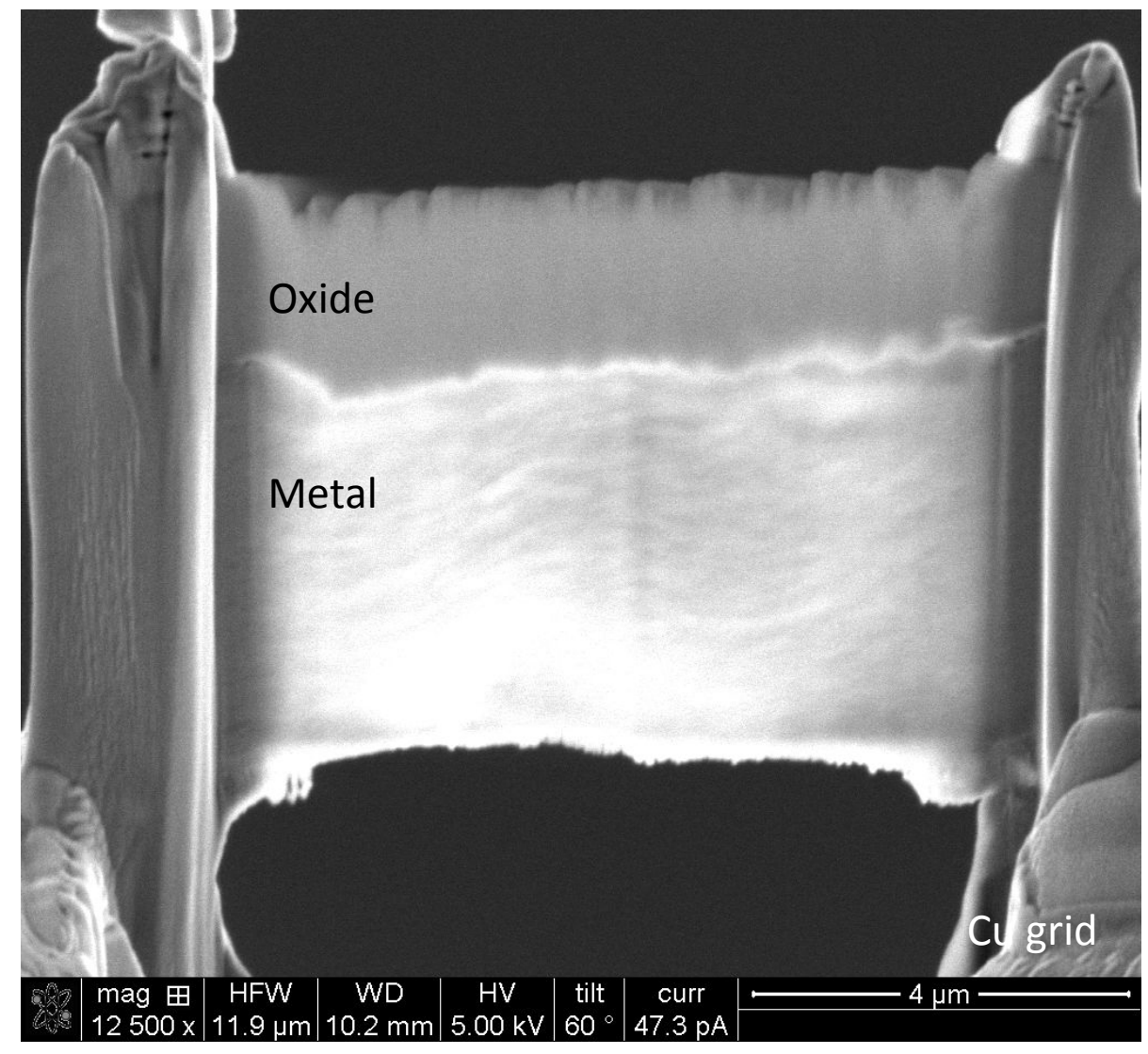

Figure 2: Scanning Electron Microscope (SEM) image of electron transparent FIB sample prepared by the in-situ lift out method. Oxide formed on Zircaloy-2 oxidised in water at 350 ${ }^{\circ} \mathrm{C}$ for 55 days.
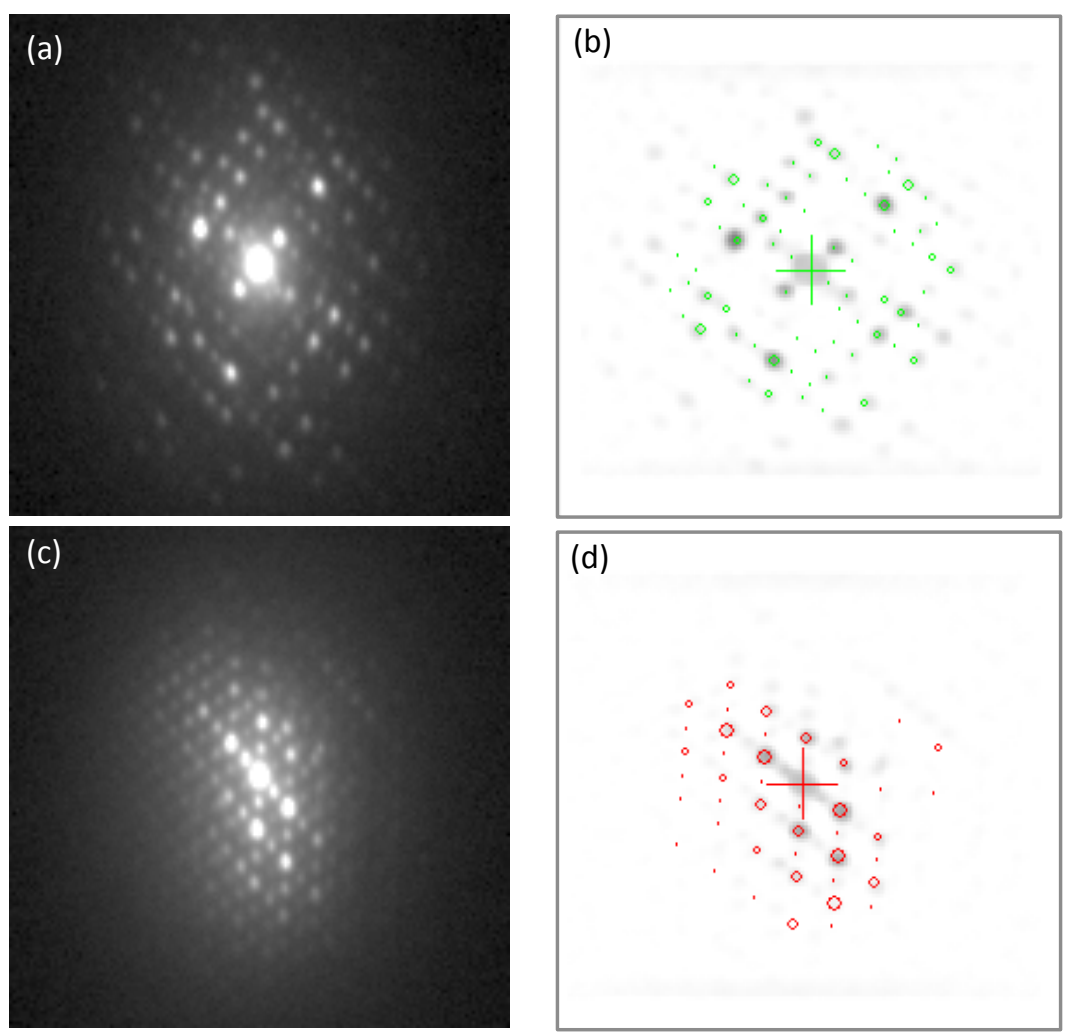
Figure 3: Typical experimental diffraction patterns and matched templates used for phase analysis, (a) and (b) show measured and calculated patterns for the monoclinic phase respectively (phase reliability $=35$, orientation reliability $=37$ ), (c) and (d) show measured and calculated patterns for the tetragonal phase (phase reliability $=$ 16, orientation reliability $=33$ ).
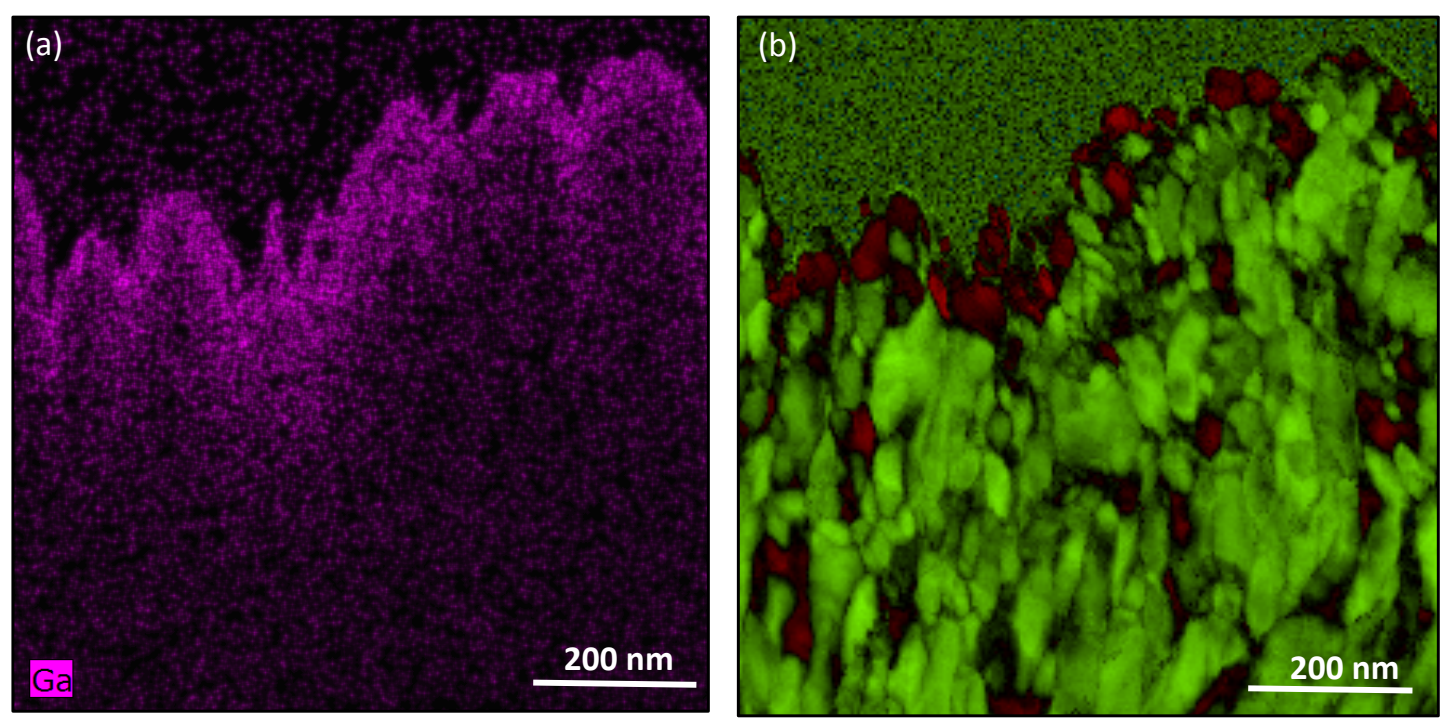

Figure 4: Equiaxed grain region of autoclave formed oxide without irradiation (a) Chemical map showing $\mathrm{Ga}^{+}$implantation in top surface of lamella and (b) corresponding phase map showing tetragonal stabilisation in implanted region. 

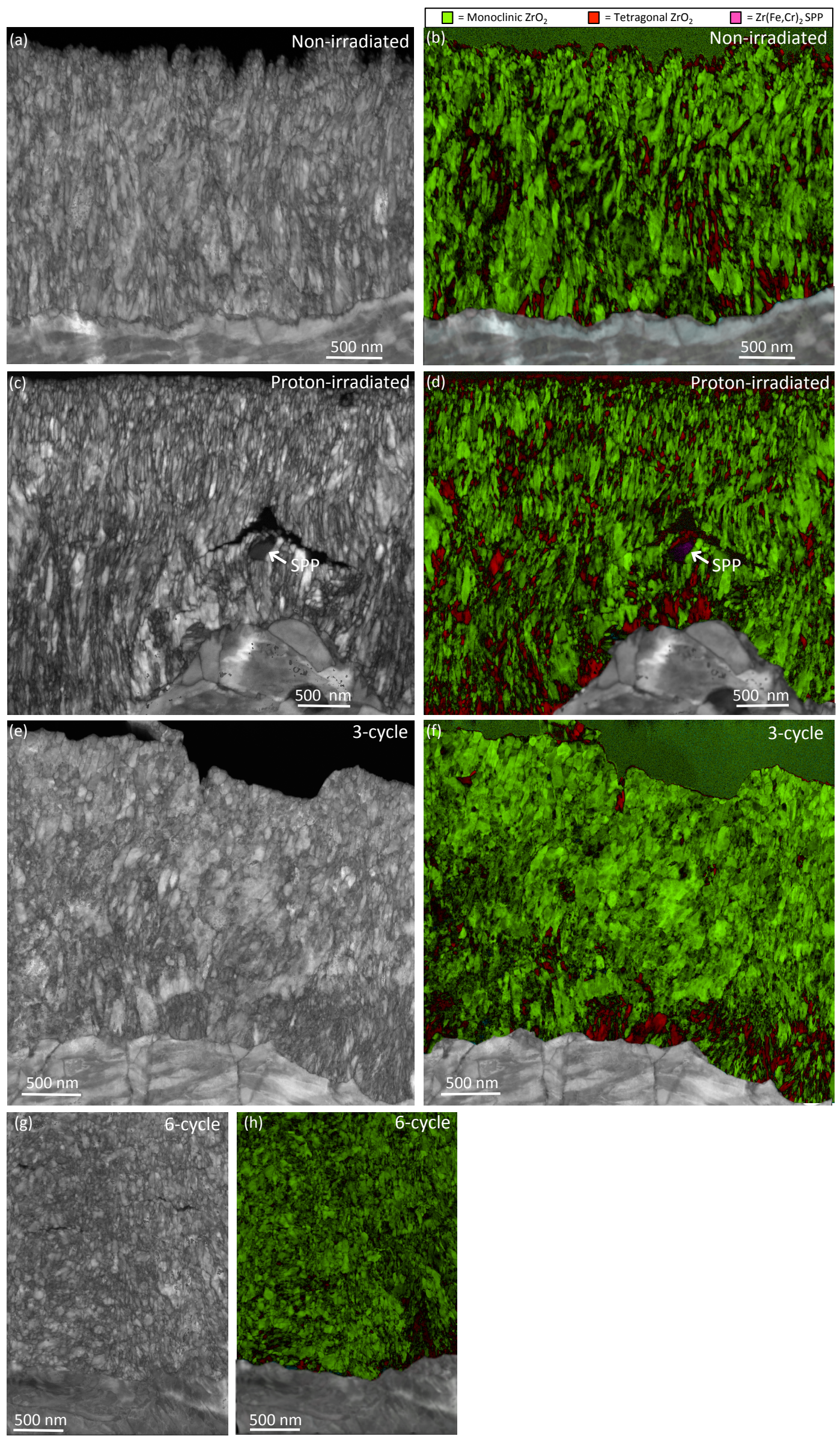
Figure 5: Index maps for oxide formed on (a) Zircaloy-2 oxidised in water at $350{ }^{\circ} \mathrm{C}$ for 55 days, (c) autoclave oxide exposed to proton irradiation, (e) oxide formed after 3 cycles in reactor and (g) oxide formed after 6 cycles in reactor. Corresponding phase maps are shown in figures (b), (d), (f) and (h). Monoclinic grains are shown in green, tetragonal in red and an indexed SPP as pink according to legend. 

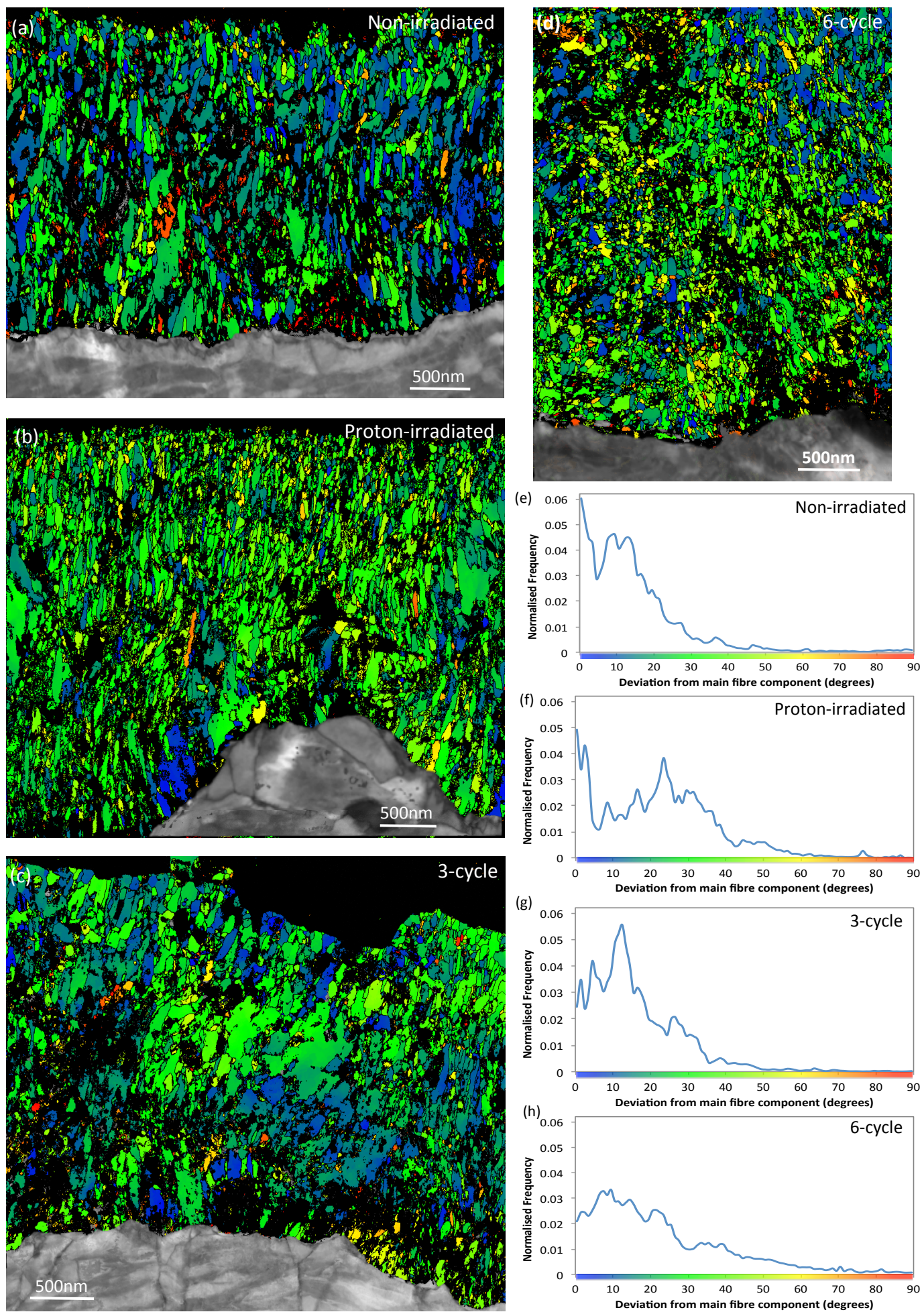

Figure 6: High reliability (threshold = 10) monoclinic orientation maps oxide formed on (a) Zircaloy-2 oxidised in water at $350^{\circ} \mathrm{C}$ for 55 days, (b) autoclave oxide exposed to proton irradiation, (c) oxide formed after 3 cycles in reactor and (d) oxide formed after 6 cycles in reactor. The grey region at the bottom of each image shows the metal

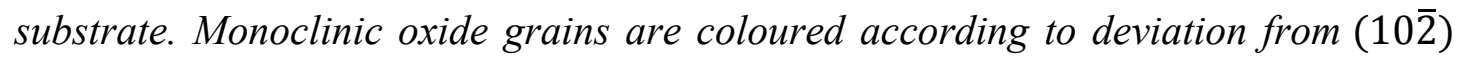
fibre component as shown in histograms (e) - (h). 

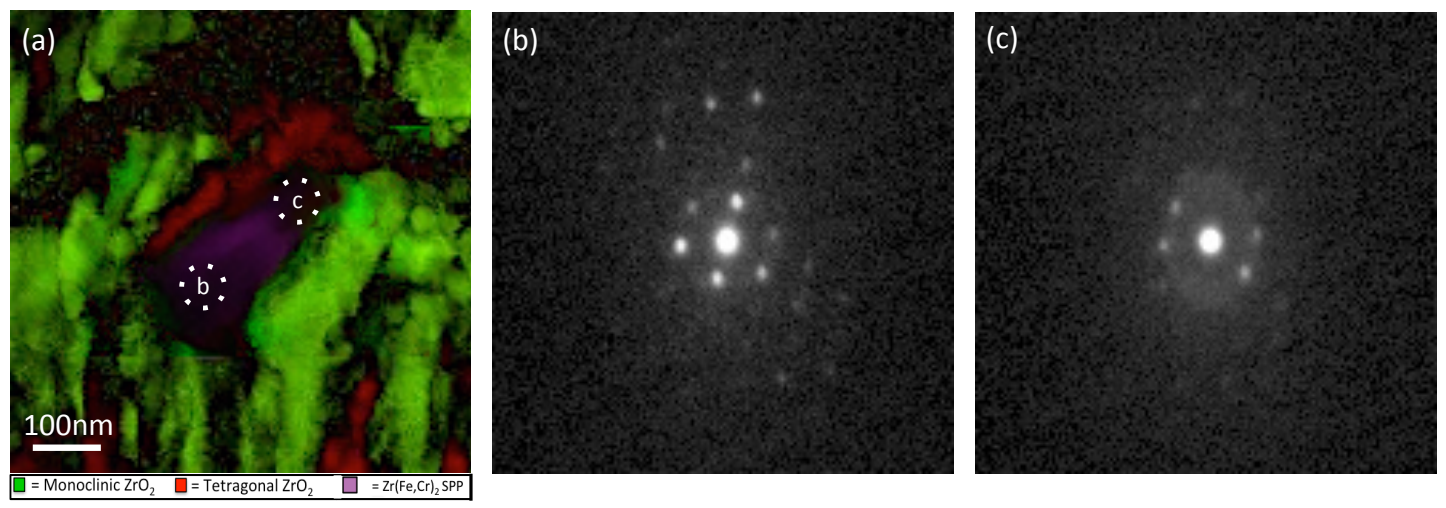

Figure 7: (a) Electron diffraction patterns acquired at different locations in an $\mathrm{Zr}(\mathrm{Fe}, \mathrm{Cr})_{2} \mathrm{SPP}$ located in the autoclave oxide exposed to proton irradiation, (b) crystalline pattern towards the bottom of particle, (c) amorphous rings visible towards the top (outer oxide).
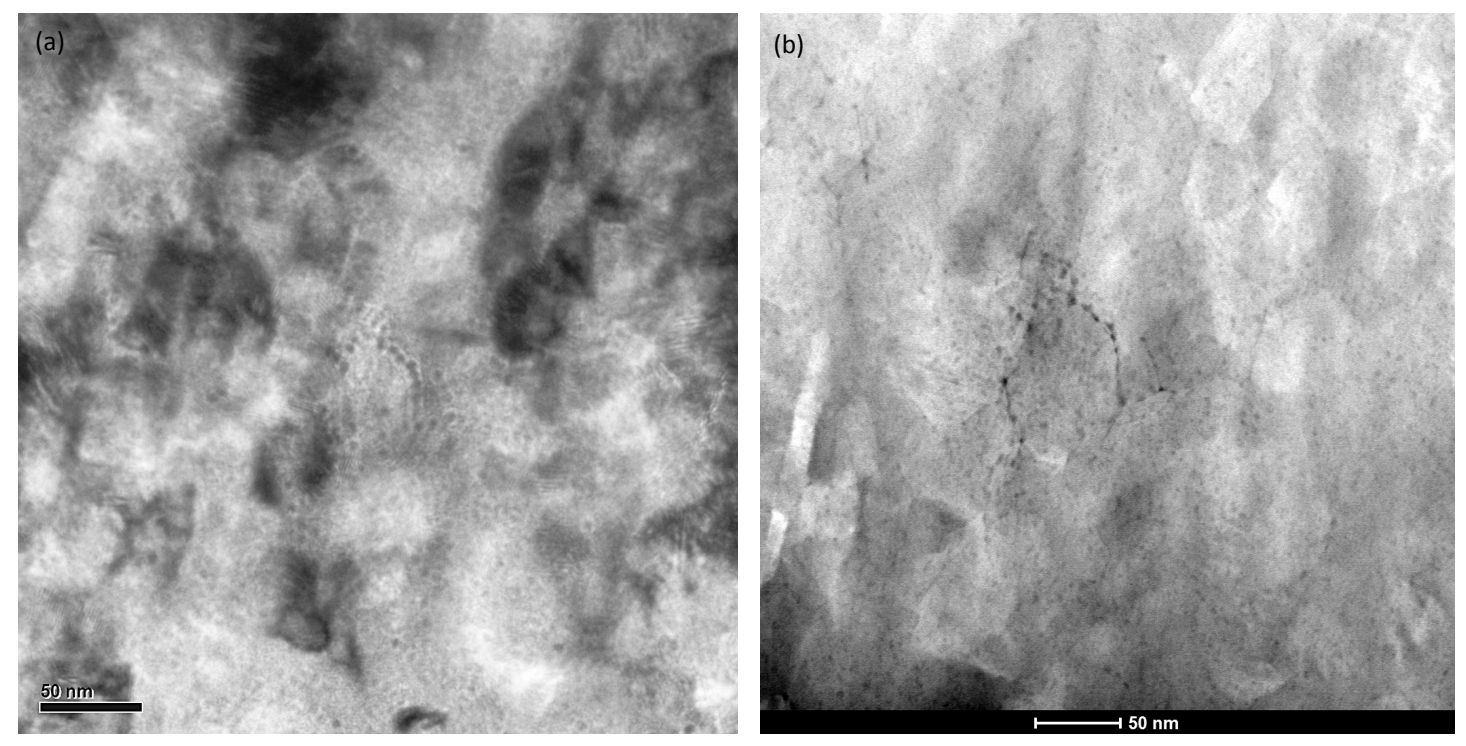

Figure 8: Nanoporosity in oxide formed on Zircaloy-2 after 3 cycles in reactor, (a) overfocus brightfield TEM image and (b) HAADF STEM image of same region approximately $1 \mu \mathrm{m}$ from the metal-oxide interface. 

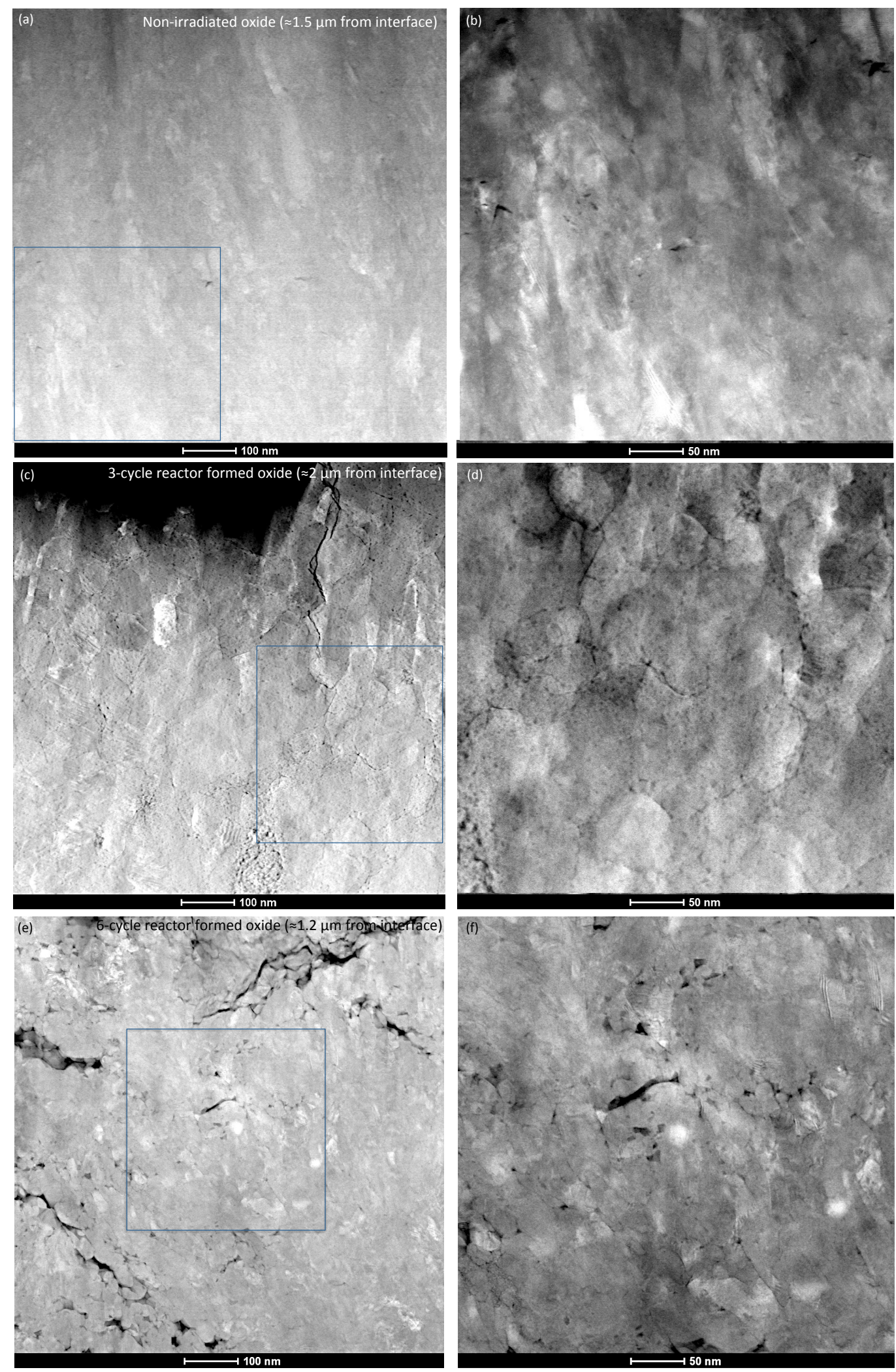

Figure 9: HAADF STEM images showing different levels of porosity in oxides formed on (a) and (b) Zircaloy-2 oxidised in water at $350{ }^{\circ} \mathrm{C}$ for 55 days ( 1.5 $\mu \mathrm{m}$ from the metal-oxide interface), (c) and (d) oxide formed after 3 cycles in reactor ( $2 \mu \mathrm{m}$ from 
the metal-oxide interface), (e) and (f) oxide formed after 6 cycles in reactor $(\sim 1.2 \mu \mathrm{m}$ from the metal-oxide interface). Oxide growth direction is top to bottom in all images.
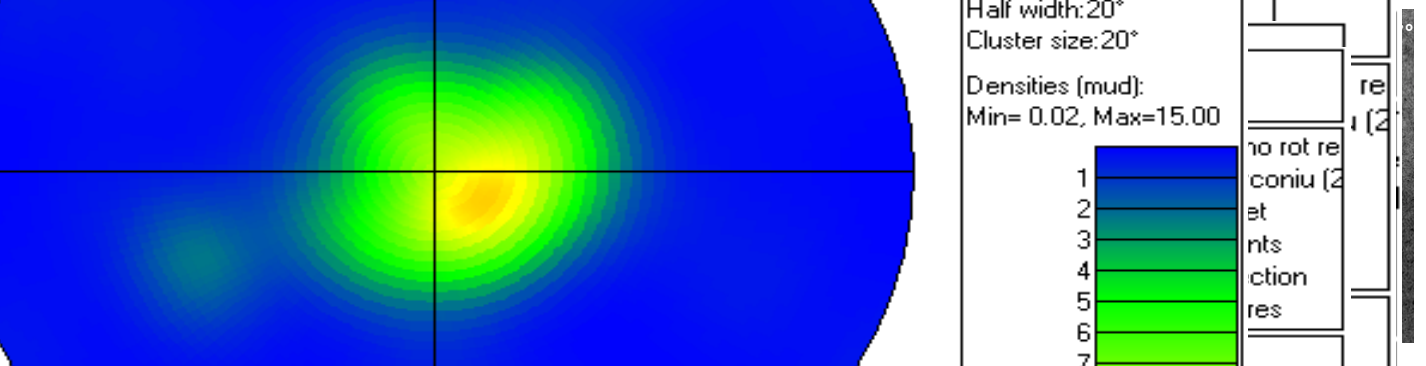

Figure 10: HAADF STEM images showing intergranular porosity around a single equiaxed grain in the outer region of the 3-cycle oxide at various tilt angles.
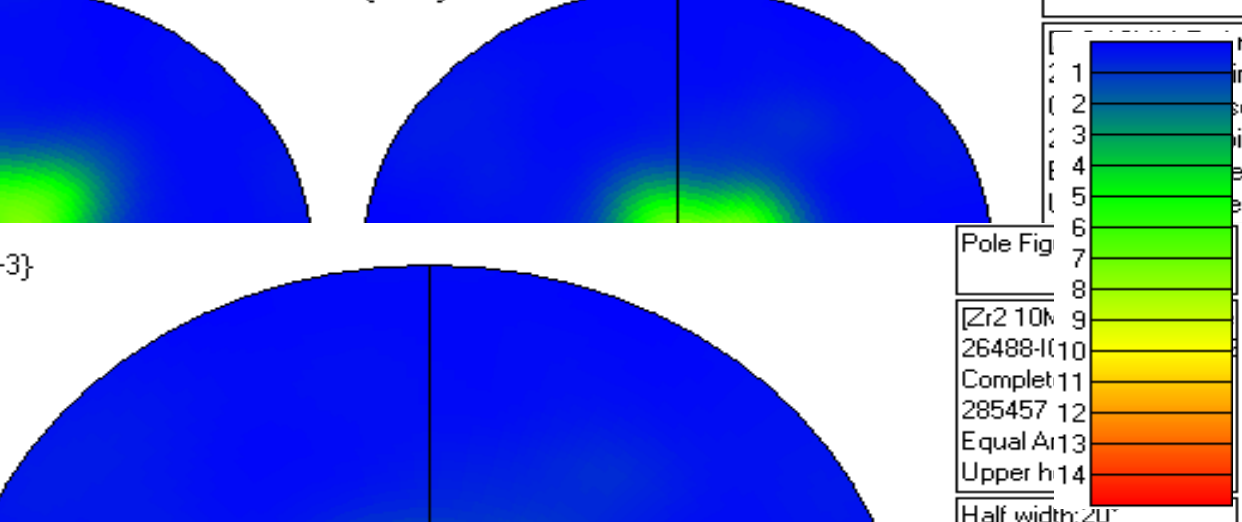

Figure 11: (001) tetragonal pole figures from oxide formed on (a) non-irradiated Zircaloy-2 oxidised in water at $350{ }^{\circ} \mathrm{C}$ for 55 days (max. intensity $=13.66$ ) and (b) proton-irradiated Zircaloy-2 (max. intensity $=4.43)$. Contour levels are in units of MUD (Multiples of uniform distribution) as shown in legend and axial/radial directions of cladding tube are indicated. 


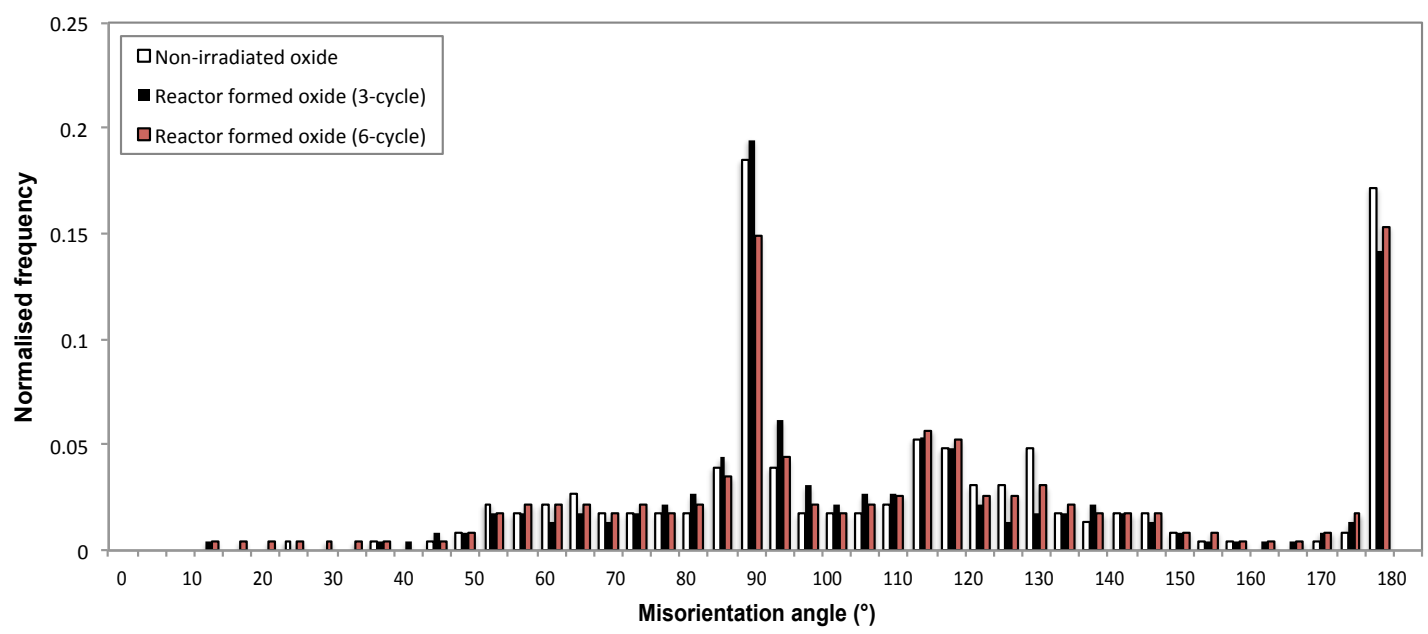

Figure 12: Comparison of misorientation angle distributions for monoclinic grain boundaries formed on non-irradiated Zircaloy-2 and in reactor for 3 and 6 cycles. 